\title{
Squirrel Monkey Lateral Thalamus. II. Viscerosomatic Convergent Representation of Urinary Bladder, Colon, and Esophagus
}

\author{
Johannes Brüggemann, Ting Shi, and A. Vaina Apkarian \\ Department of Neurosurgery, Computational Neuroscience Program, SUNY Health Science Center at Syracuse, \\ Syracuse, New York 13210
}

The response properties of 106 visceroceptive lateral thalamic neurons were investigated in anesthetized squirrel monkeys. Most neurons were located in the ventral posterior lateral nucleus (VPL), and a smaller number of cells was also found in a variety of thalamic nuclei around VPL. Ninety $(85 \%)$ of these cells responded to distension of the urinary bladder, the distal colon, and/or the lower esophagus. The majority of the visceral-responsive cells also had convergent somatic and multivisceral responses (71\% of the $85 \%)$. A small population (6\%) was visceral specific; that is, these neurons were not activated with somatic stimuli. Visceral responses were excitatory, inhibitory, or mixed, and most were either visceral nociceptive specific $(65 \%)$ or visceral wide-dynamic-range type $(34 \%)$. Very few visceral responses $(1 \%)$ could be classified as low threshold. The incidence of these response types were highly dependent on the specific viscus stimulated. Most visceral responses were able to code stimulus duration and intensity. The majority $(69 \%)$ of the visceroceptive neurons had somatic lowthreshold convergent input mainly from the surface of the lower body. The somatic receptive field locations and the somatic response properties seem unrelated to the convergent visceral input and the visceral response properties, although there were some exceptions. No obvious viscerotopical organization was found in VPL. The results lead us to propose two different modes of representation for processing of and distinguishing between visceral and somatic inputs: a distributed population code for visceral inputs, and a local code for somatic inputs. Based on these codes, we discuss a new hypothesis for referred pain.

IKey words: electrophysiology, visceral, ventral posterior nuclei, VPL, pain, nociception, referred pain, distrlbuted coding]

Visceral representation in the PNS, spinal cord, and brainstem have become major foci of investigation over the last decade. However, very little is known about visceral representation in

\footnotetext{
Received Dec. 16, 1993; revised May 3, 1994; accepted May 10, 1994.

We appreciate the technical help of Dr. A. Stea and R. T. Stevens. The complexity measures were a result of exciting discussions with Dr. D. R. Chialvo. We greatly appreciate the help of Dr. Paul R. Sheehe in the combinatorial calculations. We thank Drs. C. Vahle-Hinz and C. J. Hodge for reading an earlier version of the manuscript. This research was funded by the Department of Neurosurgery and a grant from the Perkins Foundation. J.B. was partially supported by a FeodorLynen fellowship of the Alexander von Humboldt-Foundation (Gcrmany).

Correspondence should be addressed to Dr. A. V. Apkarian, SUNY Health Science Center at Syracuse, Neurosurgery Research Laboratory, 3118 WSK Hall, 766 Irving Avenue, Syracuse, NY 13210.

Copyright $(C) 1994$ Society for Neuroscience $0270-6474 / 94 / 146796-19 \$ 05.00 / 0$
}

the thalamus. Visceral primary afferents constitute a unique population distinct from the somatic primary afferents (c.g., lcss than $0.5 \%$ of the pelvic afferents branch and innervate the skin and viscera; Häbler et al., 1988). Also the coding strategies used by the somatic and visceral systems in the PNS are distinct. Somatic primary afferents have different fiber populations subserving various stimulus modalities (e.g., touch, nociception). In contrast, many mechanoceptive primary visceral afferents have "intensity-coding" properties, that is, monotonic stimulus response curves over both innocuous and noxious ranges (see, e.g., Sengupta et al., 1989, 1990). Intensity-coding somatic primary afferents have not been found in the normal somatic PNS. Thus, at the level of the PNS, somatic and visceral information is transmitted through independent channels, and the idea of Sinclair et al. (1948) that referred pain from the viscera may be mediated through branching somatovisceral afferents has become untenable, which forces us to look for central mechanisms for referred pain (Ruch, 1946).

In contrast to the PNS, there is a high degree of somatovisceral convergence at the level of the spinal cord (Cervero and Tattersall, 1986). There is no convincing evidence for the existence of a significant population of visceral-specific neurons in the spinal cord (Rucker et al., 1984), but several studies have demonstrated that somatovisceral neurons can have also viscerovisceral convergent inputs (Milne et al., 1981; McMahon and Morrison, 1982a,b; Berkley et al., 1993a). The somatovisceral spinal cord neurons can have non-nociceptive or nociceptive somatic responses, although the majority exhibit somatic nociceptive responses (see Cervero and Tattersall, 1986). Most of these spinal cord viscerosomatic cells have intensity-coding type responses to visceral stimuli (Milne et al., 1981; McMahon and Morrison, 1982a,b).

The spinothalamic tract is assumed to be the most important route for the transmission of spinal cord visceral information cephalad (Milne et al., 1981; Ammons et al., 1985; Brennan et al., 1989), but other spinal cord tracts also participate in visceroception, including the dorsal column pathway (Yamamoto et al., 1956; Rigamonti and Hancock, 1974, 1978; Hubscher and Berkley, 1992), the spinoreticular (Foreman et al., 1984; Hobbs et al., 1990), and the spinomesencephalic tracts (Yezierski and Broton, 1991). Inconsistent results are reported for the spinocervical tract (Rigamonti and De Michelle, 1977; Cervero and Iggo, 1978; McMahon and Morrison, 1982a,b).

The nucleus of the solitary tract is the primary termination site for the vagal afferents. This area together with the parabrachial nucleus form the primary viscerotopic ${ }^{1}$ organization in the

\footnotetext{
'Viscerotopy, similarly to somatotopy, is the orderly and segregated representation of different internal organs, within any given level of the CNS.
} 
brainstem (Cechetto, 1987). These regions receive spinal cord somatic inputs (Blomqvist et al., 1989), demonstrate somatovisceral convergence that has not been extensively studied (Person, 1989), and project to the thalamus (Berkley and Scofield, 1990).

Most earlier studies of visceral inputs to the thalamus have been done in nonprimates, using electrical stimulation of visceral nerves (Dell and Olson, 1951a,b; Patton and Amassian, 1951; Aidar et al., 1952; McLeod, 1958; Chernigovskiy, 1967; Taguchi et al., 1987; Yokota et al., 1987; Asato and Yokota, 1989; Zagami and Lambcrt, 1990; Brüggemann et al., in press). There are other studies where the response properties of thalamic neurons were investigated using natural stimulation of the viscera, in the cat (Emmers, 1966; Carstens and Yokota, 1980; Davis and Dostrovsky, 1988; Zagami and Lambert, 1990; Brüggemann et al., 1993, in press), rat (Rogers et al., 1979), and monkey (Chandler et al., 1992). The majority of these investigations have been limited to exploring representation of single visceral organs, in limited areas of the thalamus, and limited subpopulations of neurons within these regions.

In the preceding companion article (Apkarian and Shi, 1994) we investigated the somatic nociceptive representation in the lateral thalamus of the squirrel monkey. The present study examines the same area of the thalamus with visceral and somatic stimulation to elucidate the interrelation between visceral and somatic representation, for innocuous and noxious stimuli. Our search strategy was to identify the lower body representation within the ventral posterolateral nucleus (VPL) using innocuous and noxious somatic stimuli, and test every isolated thalamic neuron with natural visceral stimuli. These were graded distensions of the urinary bladder, the distal colon, and the lower esophagus. Our working hypotheses were as follows. (1) Viscerotopy: there is a viscerotopic arrangement in the lateral part of the thalamus. (2) Coregistered somatic and visceral topographies: the viscerotopic arrangement is in register with the somatotopic organization of the region. For example, we assumed that the bladder and the colon would be represented in the somatic lower body portion of the lateral thalamus. Moreover, we expected that neurons with excitatory inputs from the pelvic organs would be inhibited by esophagus distension and vice versa, as shown for spinal cord neurons (e.g., Brennan et al., 1989; Hobbs et al., 1992). (3) Corresponding somatic and visceral response types: The visccral non-nociccptive-responsive representation is convergent on somatic non-nociceptive cells. Conversely, the somatic nociresponsive neurons exhibit visceral nociceptive responses as well. The results demonstrate that all three hypotheses were, at least partially, wrong.

\section{Materials and Methods}

Anesthesia and preparations. The experiments were carried out in five female adult squirrel monkeys. Before surgery, the animals were premedicated with atropine $(0.5 \mathrm{mg}$, s.c.) and antibiotics (Rocephin, 75 $\mathrm{mg} / \mathrm{kg}$, i.m.). Anesthesia was induced by ketamine $(30 \mathrm{mg} / \mathrm{kg}$, i.m.). Dexamethasone $(0.25 \mathrm{mg} / \mathrm{kg}$, i.v., twice daily) was injected to prevent edema. Anesthesia was maintained by intravenous injections of $70 \mathrm{mg} /$ $\mathrm{kg} \alpha$-chloralose (first day) followed by additional doses of $17.5-35 \mathrm{mg}$ as required (the following days). Nembutal drip (0-10 $\mathrm{mg} / \mathrm{kg} / \mathrm{hr}$ ) was applied in lactated Ringer's (with $5 \%$ dextrose) and drip rate controlled to suppress withdrawal reflexes to pinching the interdigital skin.

The housing, care, and surgical procedures followed the institutional guidelines established by the Committee for the Humane Use of Animals. The right femoral vein and artery were cannulated for drug administration and blood pressure measurements, respectively. The trachea was cannulated for artificial respiration. Double barreled balloon catheters (made from polyethylene tubing, $2.4 \mathrm{~mm}$ o.d., $1.7 \mathrm{~mm}$ i.d., and condoms) were inserted into the distal colon and the lower esophagus. Through one of the ports pressure stimuli (manometer-controlled pressed air applied to a 2 liter glass container filled with 1 liter of saline, or by lifting this container to different heights above the organs) were applied. Through the second port the intraluminal pressure was measured. The urinary bladder was cannulated via the urcthra by a doublebarreled catheter without a balloon, made from a cat catheter $(1 \mathrm{~mm}$ o.d., $0.5 \mathrm{~mm}$ i.d., used for pressure measurement) and a polyethylene tube (1.7 mm o.d., $1.2 \mathrm{~mm}$ i.d., used for pressure application).

The animal's head was positioned in a stereotaxic holder with ear bars, which were removed after another holder was fixed to the occipital pole of the skull by screws and dental cement. The stereotaxic position of the head thereby was preserved while potentially noxious stimuli from the ear bars were avoided. A small craniotomy was performed over one hemisphere to gain access to the thalamus.

All animals breathed spontaneously and the end-tidal $\mathrm{CO}_{2}$ concentration was measured continuously as well as the arterial blood pressure. Body core temperature was measured and maintained within the physiological range. All recordings were done in the unparalyzed anesthetized animals (see preceding companion article).

Recordings and stimuli. Parylene-coated tungsten microelectrodes (impedance at $1000 \mathrm{~Hz}$ : $1.5 \mathrm{M} \Omega$; Micro Probe Inc., Clarksburg, MD) were used for extracellular single- and multiunit recordings. Only those units were characterized in detail whose neural activity was isolated and originated from the soma-dendritic region, as judged from the shape and duration of the action potentials. The neuronal signals were amplified, filtered (bandpass 190-19,000 Hz), displayed on an oscilloscope, photographed, and stored on FM tape. Peristimulus time histograms (PSTHs; bin width of $1 \mathrm{sec}$ ) were generated by means of a window discriminator interfaced to a personal computer.

The distal colon and the lower esophagus were stimulated by distension via balloons filled with saline at room temperature. The balloons were made from latex condoms that had been distended several times before the experiment to assure intactness and to make them distendable to a diameter of about $5 \mathrm{~cm}$ without an increase in intraluminal pressure when immersed in a waterbath. Thus, the measured increases in intraluminal pressure were due to increases in the tension within the walls of the viscera and not the latex balloons. The bladder was stimulated directly through the bigger port of the catheter. Intraluminal pressures were increased maximally to $100 \mathrm{~mm} \mathrm{Hg}$ for $10-30 \mathrm{sec}$.

Before any visceral stimuli were applied, the lateral thalamus was mapped to determine the low-threshold somatic representation area of the abdominal and hindlimb regions in VPL (four experiments), and in and around the ventral posteromedial nucleus (VPM; one experiment) to test neurons with trigeminal inputs. Neurons with somatic receptive fields and/or ongoing activity were then tested with innocuous or noxious distension of the urinary bladder, the distal colon, and the lower esophagus. For visceroceptive ncurons the somatic response properties were determined in detail by tapping, brushing, and application of nonnoxious pressure and noxious pinch with anatomical forceps or squeeze of deep structures. Then graded pressure stimuli were applied to each of the three viscera to determine the response threshold of the thalamic neurons and the stimulus/response relationship to suprathreshold stimuli. In a subpopulation of cells thermal stimuli were also applied to the skin with a Peltier element (range of $0-54^{\circ} \mathrm{C}, 20-40 \mathrm{sec}$ duration), with hot brass rods (about $55^{\circ} \mathrm{C}$ ), or ice cubes. Stimuli were regarded as noxious when the intensities used were painful to the experimenter. The duration of most mechanical and thermal stimuli was about $10 \mathrm{sec}$. Inputs from deep tissues were tested by flexing joints and by probing and squeezing muscles.

Data analysis. PSTHs of the neuronal activity were obtained by means of a window discriminator and pcrsonal computer. The original spike and intraluminal pressure data were stored on tape and analyzed on line and off line. Neuronal activities before and during stimulation were compared. The mean change in activity was considered a response only if the stimulus response was greater than $30 \%$ from baseline and was statistically significant ( $t$ test, $p<0.05$ ).

Data analysis: classification of somatovisceral and viscerovisceral convergent inputs. We classified the lateral thalamic neurons according to their somatic and visceral response properties. Cells exhibiting the highest rate of discharge due to non-noxious somatic stimulation (brush, touch, pressure) were classified as somatic low-threshold (LTs) type. Cells responding to non-noxious as well as noxious somatic stimulation and exhibiting their highest neuronal activity at noxious intensities were 
Table 1. Minimal intraluminal pressures (in $\mathrm{mm} \mathrm{Hg}$ ) that have been reported to elicit non-nociceptive and nociceptive sensations (adapted from Jänig and Morrison, 1986)

\begin{tabular}{|c|c|c|c|}
\hline & Bladder & Colon & $\begin{array}{l}\text { Esoph- } \\
\text { agus }\end{array}$ \\
\hline Non-nociceptive threshold & 2 & 8 & 3 \\
\hline Nociceptive threshold & $\geq 30$ & $\geq 40$ & $\geq 40$ \\
\hline
\end{tabular}

classified as wide-dynamic-range (WDRs) type. Cells that responded only to noxious somatic stimuli were classified as nociceptive-specific (NSs) type.

Unit responses at various intraluminal pressures were used to distinguish between the visceral response types (Table 1). Cells having their highest discharge rate below the noxious ${ }^{2}$ threshold for a given viscus were classified as visceral low-threshold (LTv) type. When cells encoded non-noxious and noxious intensity levels in a graded manner they were classified as visceral wide-dynamic-range (WDRv) type. ${ }^{3}$ Cells responding only to noxious distensions of a given viscus were classified as visceral nociceptive-specific (NSv) type. Values given in Table 1 were adapted from Jänig and Morrison (1986) and represent mean pressure values reported in a number of animal and human studies. Neurons that responded to visceral stimuli but could not be activated from anywhere on the skin, using innocuous and noxious stimuli, were classified as visceral specific.

Somatic and visceral responses were also classified as excitatory (increased activity with stimulation), inhibitory (decreased activity with stimulation), or mixed (variable responses). There were no mixed somatic responses and very few inhibitory somatic responses. Somatic responses were classified inhibitory only if a unit had no somatic excitatory responses and the inhibitory receptive field was in continuity with the surrounding units' receptive fields. Many visceral-responsive cells exhibited complex changes in activity with repeated visceral stimulation. These units' ongoing activity would sometimes increase, sometimes decrease, and other times remain unchanged to the same visceral stimulation. Such units were classified as having mixed responses.

Based on Sherrington's reports (in Hoeher, 1940) and the reviews by Jänig and Morrison (1986) and Ness and Gebhart (1990), we assume that, on the lower body, the colon afferents (T8-L2, and S2-coccygeal) and bladder afferents (T10-L2, and S2-coccygeal) have a common spinal segmental input with somatic afferents (homosegmental) from the dorsal upper thigh extending to the upper portion of the gastrocnemius region, perianal, suprapubic, and tail areas. On the upper body, the esophagus afferents (T5-T8) share spinal inputs with somatic afferents innervating the upper body regions from the breast half way to the umbilical region. Colon and bladder upper body afferents (18-L2 and T10-L2, respectively) share somatic spinal inputs with the somatic afferents of the area from halfway above the umbilical and the breast to the upper ventral thigh.

The convergence of inputs from visceral and somatic receptive fields were classified as "proper" (in the sense of sharing the same spinal segmental inputs), "improper" or indeterminable. Such a classification was necessary because a large number of the neurons studied had an unexpectedly high degree of convergence, which did not follow the known spinal afferent input organization. This classification is done only for cells with clearly defined excitatory somatic receptive fields. Somatovisceral convergence is classified as proper, if excitatory visceral responses occur together with somatic receptive fields that include any portion of homosegmental dermatomes. Inhibitory visceral responses were classified as proper if the somatic receptive field was outside the homosegmental dermatomes for the viscus concerned. This inhibitory

\footnotetext{
${ }^{2}$ For stimuli applied on the skin, noxious refers to tissue-damaging or potentially tissue-damaging inputs. In the case of visceral stimulation, usually tissue-damaging stimuli do not induce pain perception. Instead, extreme distensions, above the natural physiological range, or distensions following inflammation are considered noxious.

${ }^{3}$ Visceral primary afferents have been classified as intensity coding when they respond at innocuous or physiological thresholds and can encode stimulus intensities in the innocuous and noxious ranges (Cervero and Morrison, 1986). Here we designate such thalamic rcsponses as WDRv to emphasize the parallels between them and the WDRs type responses.
}

Table 2. Incidence of visceroceptive neurons in the lateral thalamus

\begin{tabular}{lr}
\hline VPL & 62 \\
VPM & 4 \\
VPI & 4 \\
Zi & 3 \\
PO & 3 \\
R & 2 \\
Pulo. & 2 \\
VL & 1 \\
Not assignable & $a$ \\
Total & 9
\end{tabular}

Total

${ }^{a}$ The neurons not assignable unequivocally to one of the nuclei were located mainly on the border between the ventrobasal complex and neighboring nuclei.

visceral proper classification is based on physiologic studies showing that spinal cord neurons tend to have inhibitory inputs from visceral organs with heterosegmental afferents; e.g. thoracic spinal cord neurons with excitatory somatic inputs receive inhibitory inputs from remote viscera, such as the bladder (Brennan et al., 1989; Hobbs et al., 1992). The somatovisceral convergence is classified as improper if a given neuron exhibits excitatory responses from a specific viscus and its somatic receptive field is exclusively outside of the corresponding dermatomes for this specific viscus; that is, the somatic receptive field is from nonhomosegmental inputs. Inhibitory pelvic visceral responses with homosegmental excitatory somatic receptive field were classified as not determinable because there are central inhibitory reflexive interactions between the bladder and colon (Floyd et al., 1982).

Viscerovisceral interactions were also characterized as "proper," "improper," or indeterminable, based on the types of interactions. When the esophageal input and the pelvic inputs have opposite effects on the neuronal activity, the interaction is classified as proper. Inversely, when the esophageal and the pelvic inputs are in the same direction the viscerovisceral interactions are classified as improper. Mixed responses, that is, excitatory and inhibitory responses from the same viscus, were regarded as not determinable.

Data analysis: grammar complexity calculations. The large convergence between various viscera necessitated calculating some measure of information contributed by each organ. The responses of neurons to visceral or somatic stimuli were compressed into four types: excitatory, inhibitory, mixed, and no response $(+,-, \pm$, and 0 , respectively). With this reduction, each neuron's response can be regarded as a quaternary code for each stimulus tested. For a given track, using this code one can generate a dorsoventral sequence of symbols making up the code within that track for a specific viscus. This generates four such sequences for the three viscera tested and the somatic responses, that is, four words made up of the quaternary alphabet, for each track. Also, since the number of elements in each word (track) was short, we combined all these words (tracks) into a single word for each viscus, and for somatic responses, and generated a single large word for each. We used a metric, context-free grammar complexity to test the extent of the predictability of these sequences. This is measured by calculating the length of the smallest algorithm needed to generate a given sequence. Grammar complexity, when normalized, is a continuous scale $(0.00-1.00)$ that measures the degree of regularity, distance from 0 , or randomness, distance from 1, for a given sequence (Rapp et al., 1993).

The algorithm searches for repetitions (more than twice) of increasing length sequences of the letters of the alphabet within a word. The repeated sequences are replaced by a new code, until the minimum word is generated. The grammar complexity of the original message is the sum of the complexities of the compressed message. Each symbol contributes 1 to this sum. Exponents of repeated symbols contribute logarithmically, in base 2 . Symbols that have replaced sequences of the original alphabet are counted the same way. The sum is then normalized by the number of elements in the original word (see the examples given in Jiménez-Montaño, 1984; Rapp et al., 1993).

Since for each electrode track we generate four words, these words are considered repeated measures. The mean and standard deviation of the grammar complexity for each viscus is a relative measure of the informational contribution of each viscus, and for somatic responses, to the thalamic region independent of sampling problems and the lengths of the tracks. Since the number of elements in each word was relatively 

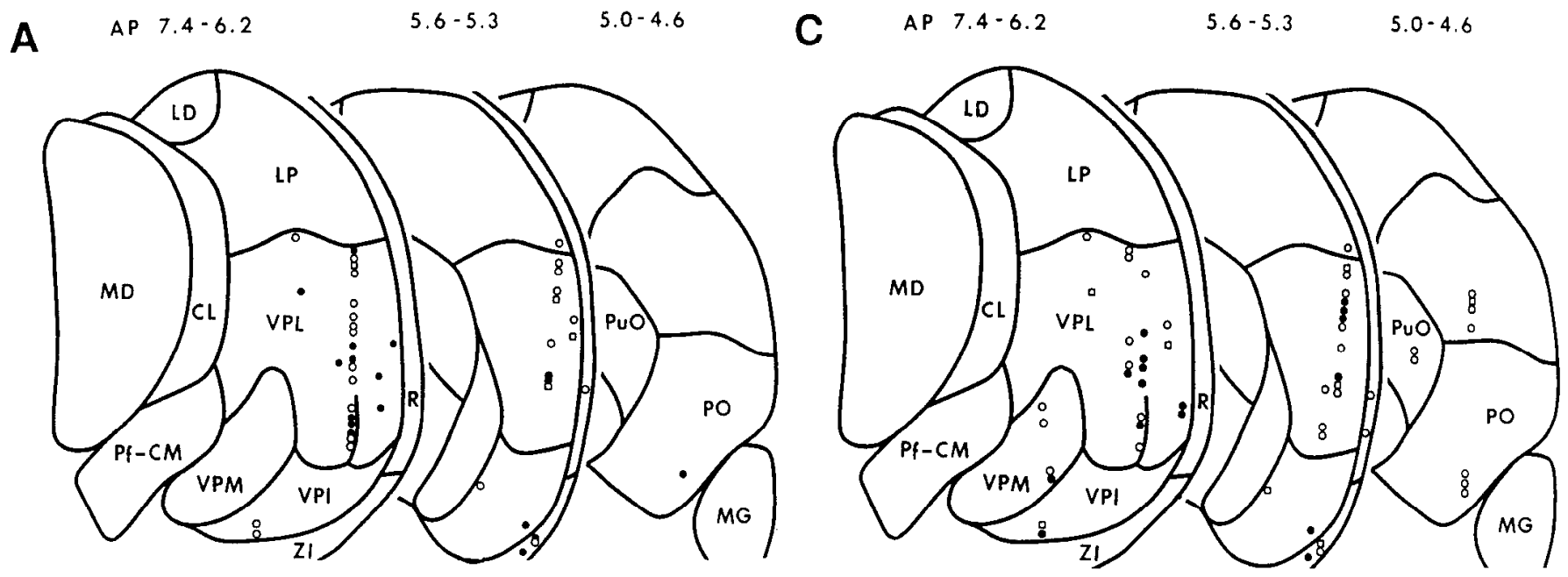

B
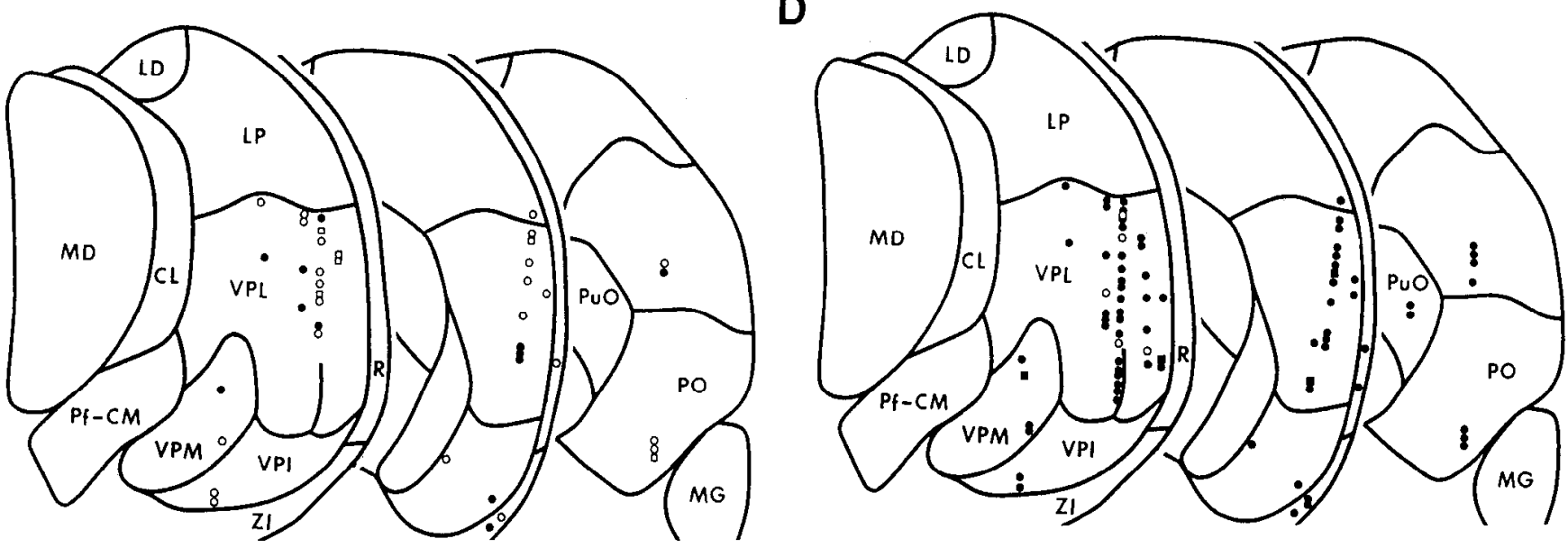

Figure 1. Distribution of the visceroceptive neurons in the lateral thalamus. $A-C$, Recording sites of neurons with excitatory (solid circles), inhibitory (open circles), or mixed (open squares) responses, with inputs from the urinary bladder $(A)$, the distal colon $(B)$, and the lower esophagus (C). Many recording sites appear more than once, since most neurons received inputs from two or three visceral organs. $D$, Recording sites of neurons with somatovisceral convergent inputs (solid circles), visceral-specific inputs (black squares), or pure somatic inputs (open circles) drawn on three schematic frontal planes $(A P$, anteroposterior level). $C L$, central lateral nucleus; $C M$, nucleus center median; $L D$, lateral dorsal nucleus; $L P$, posterior lateral nucleus; $M D$, mediodorsal nucleus; $M G$, medial geniculate nucleus; $P f$, parafascicular nucleus; $P O$, posterior complex; $P u O$, oral or anterior part of pulvinar; $V P I$, ventral posterior inferior nucleus; $V P L$, ventral posterolateral nucleus; $V P M$, ventral posteromedial nucleus; $R$, thalamic reticular nucleus; $Z I$, zona incerta.

short, only the longer sequences were used and compared to each other using repeated measures analysis of variance.

Histology. Some recording sites and some electrode penetrations in each plane were marked by electrolytic lesions $(-10 \mu \mathrm{A}$ for $10-15 \mathrm{sec})$. At the end of the experiments the animals were given a lethal dose of Nembutal $(200 \mathrm{mg} / \mathrm{kg}$, i.v.) and perfused with $0.9 \%$ saline followed by a phosphate-buffered solution of $4 \%$ paraformaldehyde $(\mathrm{pH} 7.4)$. The brain was blocked in stereotaxic frontal planes and stored in the same solution. From the blocked brain $50 \mu \mathrm{m}$ serial frontal sections were cut and alternating series were stained with cresyl violet and for cytochrome oxidase for the histological recovery of the electrolytic lesions and the reconstruction of the electrode penetrations. The recovered locations of the investigated neurons were drawn into camera lucida drawings obtained from the stained sections and assigned to the different thalamic nuclei.

\section{Results}

Lateral thalamic nuclear boundaries and nomenclature

The nuclear boundaries of the lateral thalamus were determined using the same criteria and staining procedures outlined in preceding companion article (Apkarian and Shi, 1994). The nomenclature used is the same as that described in that article.

\section{Locations of visceroceptive neurons}

One hundred six lateral thalamic neurons in five female squirrel monkeys were tested for visceral inputs from the urinary bladder, the distal colon and the lower esophagus. Ninety of these 106 cells $(85 \%)$ had excitatory or inhibitory inputs from at least one of the viscera tested. Most of the visceroceptive neurons were located in the VPL, due to the search strategy. Visceroceptive neurons were also located in the ventral posteromedial nucleus (VPM), the ventral posterior inferior nucleus (VPI), zona incerta (ZI), the posterior complex (PO), the thalamic reticular nucleus $(\mathrm{R})$, the ventrolateral nucleus (VL), or the oral part of the pulvinar (Pulo, synonym for anterior pulvinar; Table 2, Fig. 1). Nine of the visceroceptive neurons were not assigned to specific thalamic nuclei since they were located in transitional zones between VPL and the neighboring VPI or VL, or between $\mathrm{ZI}$ and $\mathrm{R}$.

In contrast to our working hypothesis 1 (viscerotopy) no segregation hetween neurons with inputs from the esophagus and the pelvic organs was found (Fig. $1 A-C$ ). Similarly, no segre- 

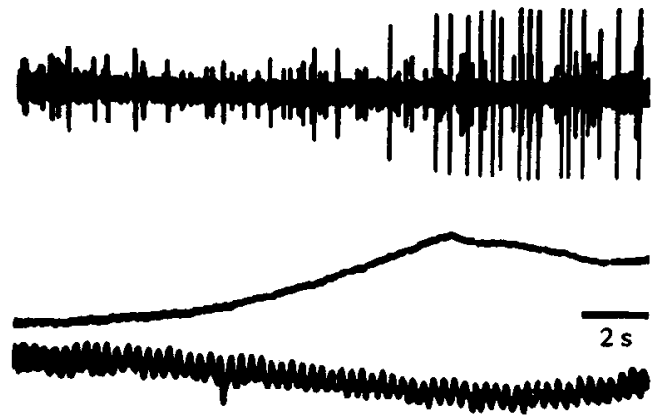

Figure 2. Oscilloscope tracings of a lateral thalamic unit activity (top), esophagus pressure (middle), and blood pressure (bottom). Distension of the esophagus to $45 \mathrm{~mm} \mathrm{Hg}$ resulted in increased unit activity and transient decrease in mean blood pressure from 105 to $100 \mathrm{~mm} \mathrm{Hg}$. The total time displayed is $20 \mathrm{sec}$.

gation between neurons characterized as visceral specific, somatovisceral, or pure somatic was found (Fig. 1D).

\section{Response properties: general}

The visceral stimuli used ranged from the non-noxious to noxious intensities (generally from 0 up to $70 \mathrm{~mm} \mathrm{Hg}$; maximally $100 \mathrm{~mm} \mathrm{Hg}$ in a few cases). Distension of one viscus had little or no effect on other intraluminal pressures. Distension of pelvic viscera occasionally resulted in a small increase in heart rate and blood pressure (less than $5 \mathrm{~mm} \mathrm{Hg}$ ), which were uncorrelated to the neuronal responses. Esophagus distension more frequently resulted in transient decreases in blood pressure, mostly less than $5 \mathrm{~mm} \mathrm{Hg}$; in four of about 300 trials the decrease was larger than $10 \mathrm{~mm} \mathrm{Hg}$. Occasionally esophagus distension resulted in increased blood pressure; only seven of about 300 trials showed blood pressure increases larger than $10 \mathrm{~mm} \mathrm{Hg}$.

Figure 2 shows the blood pressure and heart rate during esophagus distension (maximum $=45 \mathrm{~mm} \mathrm{Hg}$ ), and the response of a thalamic unit to this stimulus. The blood pressure decreased by $5 \mathrm{~mm} \mathrm{Hg}$ and returned to baseline $(105 \mathrm{~mm} \mathrm{Hg}$ ) within 10 sec from this maximal decrease. The unit activity increased 4 sec prior to the maximum blood pressure decrease, just at the peak of esophagus distension. The stimulus was maintained for $50 \mathrm{sec}$ and the increased activity of the unit was sustained for this duration. Therefore, the increase in unit activity was correlated with the esophagus distension but not with the change in blood pressure.

With two exceptions all units with visceral responses were in addition tested for somatic inputs. Lateral thalamic visceroceptive cells exhibited excitatory, inhibitory and mixed responses, or no responses to stimulation of a particular viscus, with distension of all three viscera (Table 3 ). The $3 \times 4$ contingency table of viscera stimulated versus response types was statistically significant $\left(\chi^{2}=37.3, p<0.001\right)$, implying that the distribution of response types depends on the viscus stimulated. The most common visceral response was inhibition due to esophagus stimulation ( $91 \%$ were esophagus-responsive, and 44 of 80 cells were inhibited with esophagus distension; Table 3). Since most neurons were located in the lower body representation area of VPL ( 58 of 88 cells; $66 \%$ ), inhibition with esophagus stimulation is in agreement with our working hypothesis 2 (somatic and visceral coregistered topography), which assumes that remote visceral inputs should be inhibitory.

Bladder and colon distension were less effective stimuli (only
Table 3. Response types of visceroceptive lateral thalamic neurons

\begin{tabular}{lcccc} 
& Bladder & Colon & Esophagus & Total \\
\hline 0 & $40(44 \%)$ & $44(49 \%)$ & $7(9 \%)$ & $91(35 \%)$ \\
- & $26(29 \%)$ & $28(31 \%)$ & $44(55 \%)$ & $98(38 \%)$ \\
+ & $19(21 \%)$ & $12(13 \%)$ & $20(25 \%)$ & $51(20 \%)$ \\
\pm & $5(6 \%)$ & $6(7 \%)$ & $9(11 \%)$ & $20(8 \%)$ \\
Tested & 90 & 90 & 80 & 260
\end{tabular}

0 , no response; - , inhibition; + , excitation; \pm , mixed response to stimulation of a specific viscus; Tested, number of cells tested; Total, total number of responses of 106 neurons (including responses of incompletely characterized cells) to stimulation of the three viscera.

$51-56 \%$ responded). Like the esophageal responses, the responses to stimulation of pelvic organs were more often inhibitory (29-31\%; Table 3), disagreeing with working hypothesis 2 , since we expected excitatory inputs from the pelvic viscera onto neurons with locations in the lower body representation area of VPL. Excitatory responses were seen from all three viscera (13-25\%), but the ratio of excitatory versus inhibitory responses was not significantly different between the three viscera, which again is in contradiction to our working hypothesis 2 . This lack of significance together with the statistical significance of Table 3 implies that the primary difference between the responses to the three organs is in the incidence of a response rather than the specific response type.

Eleven percent of the neurons were unresponsive during certain phases of their characterization with visceral stimuli. For example, stimulating a viscus initially resulted in a robust response (excitation or inhibition), a second application of the same stimulus failed to change the ongoing activity, and a third or fourth repetition of the stimulus evoked the same robust response as seen initially. Altogether $8 \%$ (Table 3 ) of all the visceral responses were of the mixed type. This group included responses that switched between excitation, inhibition, and occasional unresponsiveness.

\section{Response properties: examples of visceroceptive cells in VPL}

Response properties of visceroceptive cells are illustrated in Figures 3-6, and 10. The responses of a visceroceptive VPL neuron with excitatory inputs from all three stimulated viscera are shown in Figure 3. The neuron was LTs type, and its somatic receptive field was located on the fifth digit of the contralateral foot. The durations of the stimuli applied to the three viscera are reflected in the changes in firing rate. Colon and esophagus distension evoked increased activity only when the intraluminal pressure exceeded $40 \mathrm{~mm} \mathrm{Hg}$. Therefore, this unit's visceral responses are presumed to be NSv type for colon and esophagus stimulation. With colon distension, the unit encoded the noxious stimulus in a graded manner. In contrast to many spinothalamic tract neurons (e.g., Brennan et al., 1989; Hobbs et al., 1992), this thalamic neuron had excitatory input from remotely located viscera, that is, from the pelvic as well as the thoracic body regions. Moreover, its somatic receptive field was located in the dermatome of the sixth lumbar spinal segment (L6, equivalent to L5 in man; Sherrington, in Hoeber, 1940). This segment, however, does not receive direct input from the lower esophagus and is not thought to play a role in pelvic pain (Jänig and Morrison, 1986). Therefore, the viscerovisceral and somatovisceral convergences were classified as improper. In addition, this neuron seemed to code exclusively nociceptive in- 

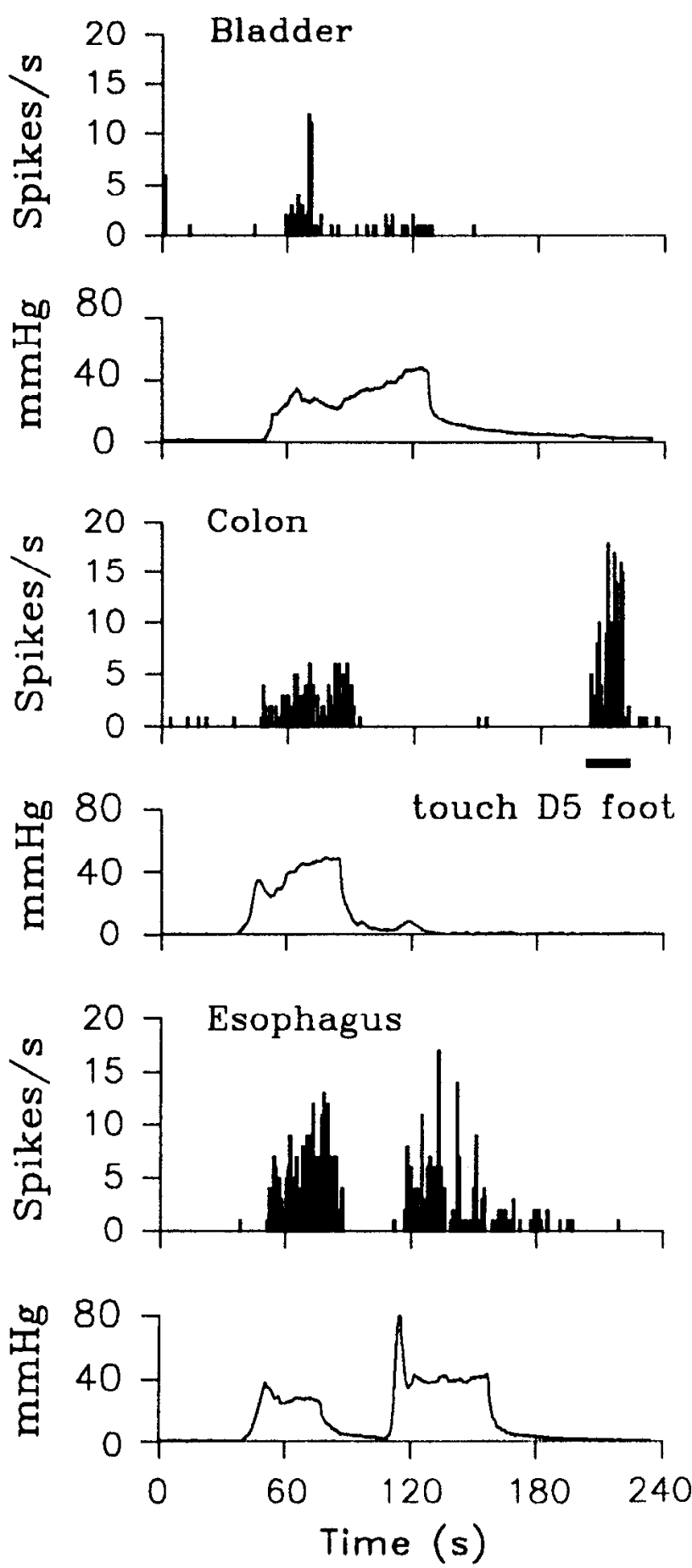

Figure 3. Peristimulus time histograms of responses of a VPL neuron to distension of the urinary bladder, the distal colon, and the lower esophagus. The responses to somatic mechanical stimulation were purely low threshold, while the responses to visceral stimulation were presumably nociceptive. Intraluminal pressures are shown below each graph.

formation at least for the colon, but exhibited purely non-nociceptive coding of somatic inputs. Therefore, the properties of this neuron contradict all three working hypotheses (viscerotopy, somatic and visceral coregistered topography, and corresponding responsc types).

Figure 4 illustrates another example of the somatovisceral response properties of a VPL neuron with a somatic receptive field on digit 3 of the foot. Thus, this neuron was also located
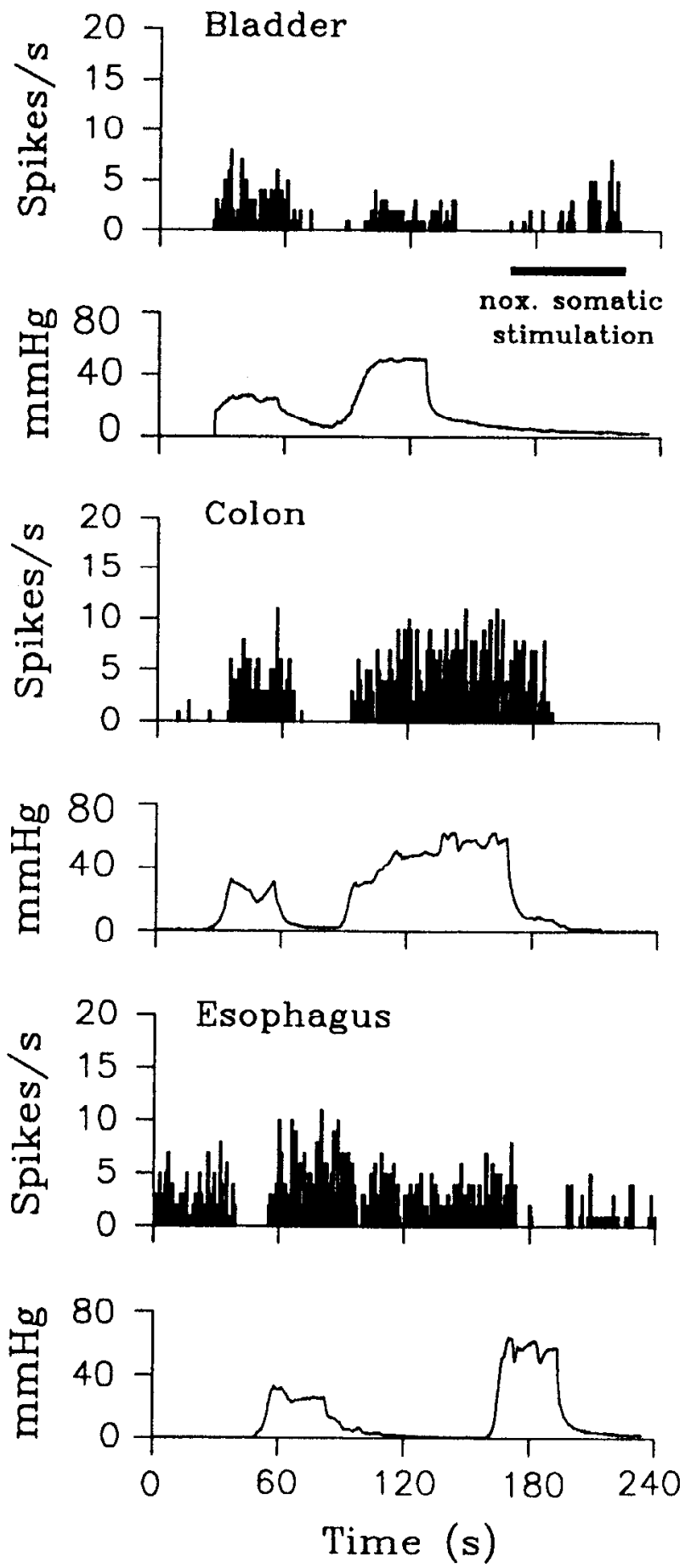

Figure 4. Peristimulus time histograms of responses of a VPL neuron to distension of the urinary bladder, distal colon, and lower esophagus. Only noxious squeezing of the knuckle of digit 3 of the contralateral foot elicited a somatic response (period of several stimulations marked with the horizontal bar). Location of the receptive field and the thalamic recording site are illustrated in Figure 6 (cell 11).

in the thalamic L6 dermatome representation area. The unit encoded the duration of the distensions from all three viscera. Encoding of stimulus intensity, however, was less consistent for the different organs. The evoked activity due to urinary bladder distension was higher at lower stimulus intensities (Fig. 4, top). However, distension of the distal colon led to a graded increase in impulse rate. The response to esophagus distension was in- 

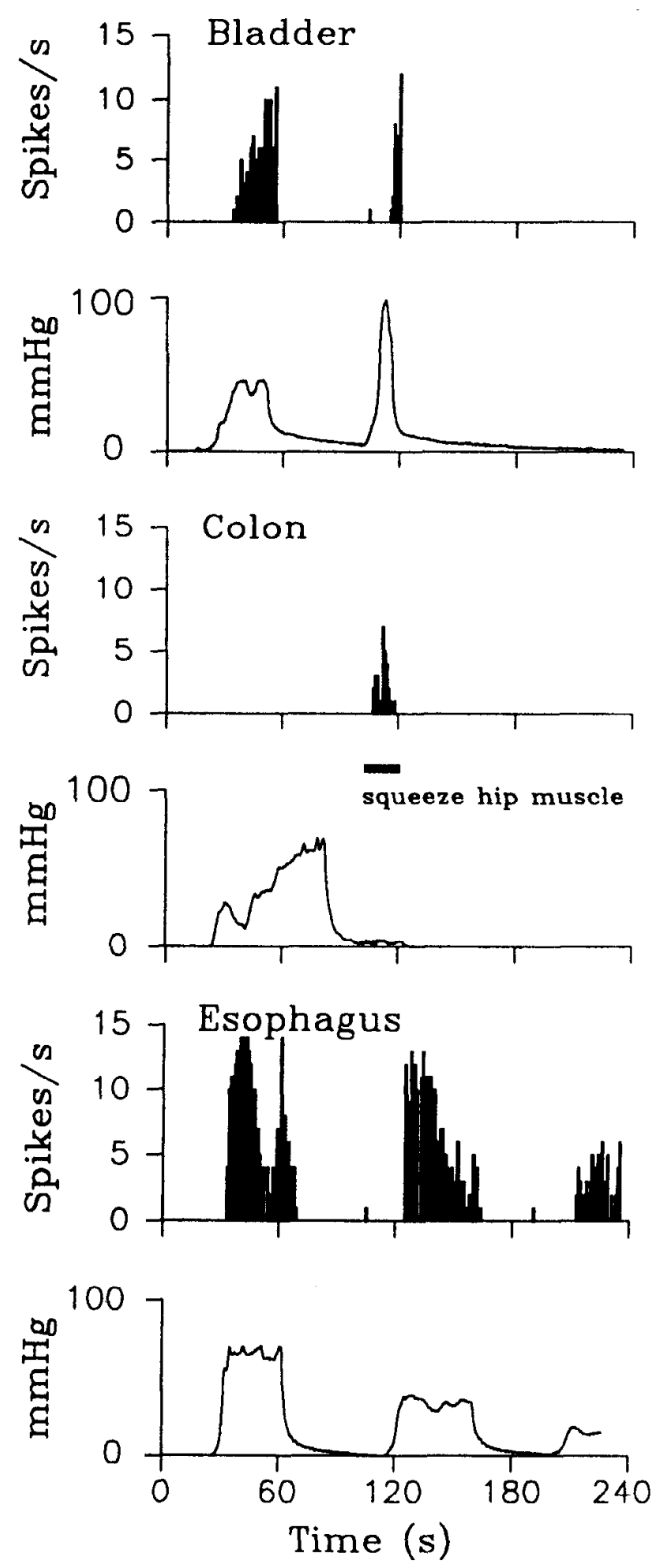

Figure 5. Peristimulus time histograms of the responses of a ZI neuron to distension of the urinary bladder and the lower esophagus. The nociceptive-specific somatic receptive field was located in the deep tissue of the hip. Distension of the distal colon had no effect. Intraluminal pressures are shown below each graph.

consistent but reproducible, classified as a mixed response. The somatic response of the neuron was NSs; only repeated noxious squeezing of the knuckle of digit 3 of the contralateral foot elicited a response. Location of the receptive field and the tha-
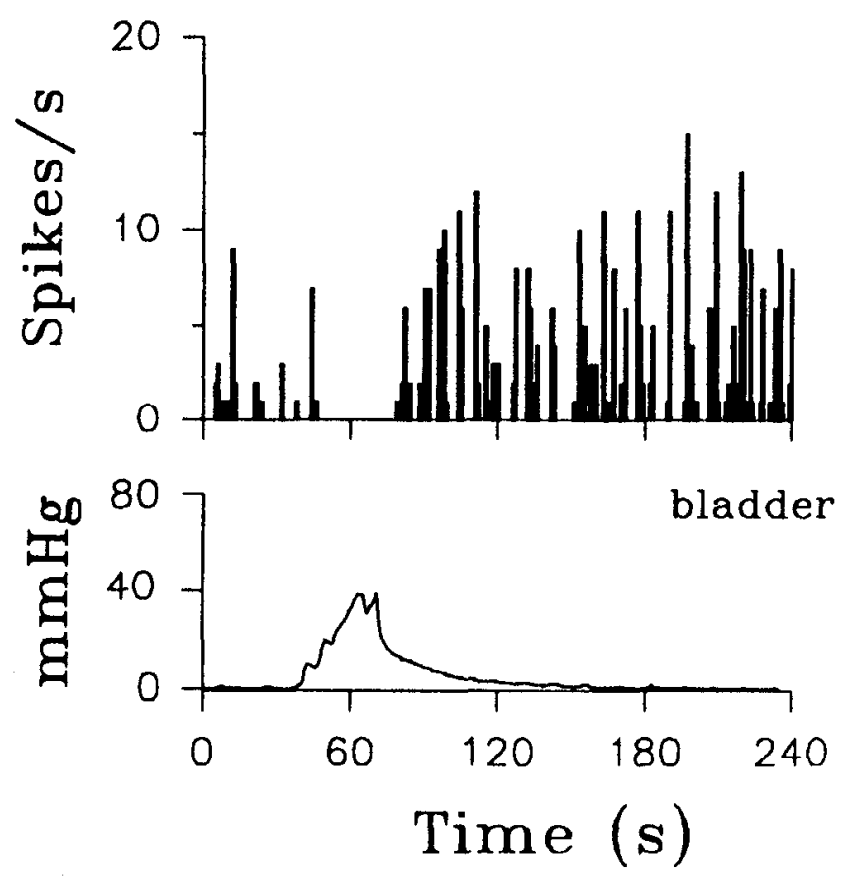

Figure 6. Peristimulus time histogram of the inhibitory response of a VL neuron to distension of the urinary bladder. Distension of the distal colon and the lower esophagus had no effect on the neuronal activity. The low-threshold somatic receptive field was located on the hip. The trace below the graph shows the recorded intraluminal pressure.

lamic recording site are shown in Figure 12 (cell 11). Similar to the response properties and receptive fields shown in Figure 3, this neuron also had improper interactions between the somatic and pelvic inputs, and an improper pelvic viscerovisceral convergence.

\section{Response properties: examples of visceroceptive cells outside $V P L$}

A small population of visceroceptive cells was found in a number of nuclei surrounding VPL (see Table 2). These arcas were not studied systematically. The response properties of these cells do not seem significantly different from those found within VPL.

The responses of a neuron recorded in the ventral thalamus in $\mathrm{ZI}$ are shown in Figure 5. This neuron had no spontaneous activity, and was found when an adjacent (visceral unresponsive) neuron was being tested. The neuron had an NSs type response from the deep tissue of the contralateral hip. The responses to distension of the urinary bladder and the lower esophagus were correlated with the durations and intensities of visceral stimuli, in a large range of intensities. Thus, this unit's responses to bladder and esophagus distension were WDRv type. Distension of the distal colon did not excite this neuron.

An example of inhibitory input from a visceral organ is shown in Figure 6. The neuron was located in VL, and its somatic receptive field was located on the hip. This unit was classified as LTs since light pressure elicited a maximal increasc in discharge rate. Distension of the urinary bladder resulted in complete inhibition of the bursting ongoing activity of this neuron, and an increased number of spikes per burst for several minutes. Esophagus or colon distension did not effect the unit's activity.

Neural activity and responsiveness as a function of time

The physiological recordings were done up to $50 \mathrm{hr}$. The effects of these long-duration recordings on spontaneous activity, on 

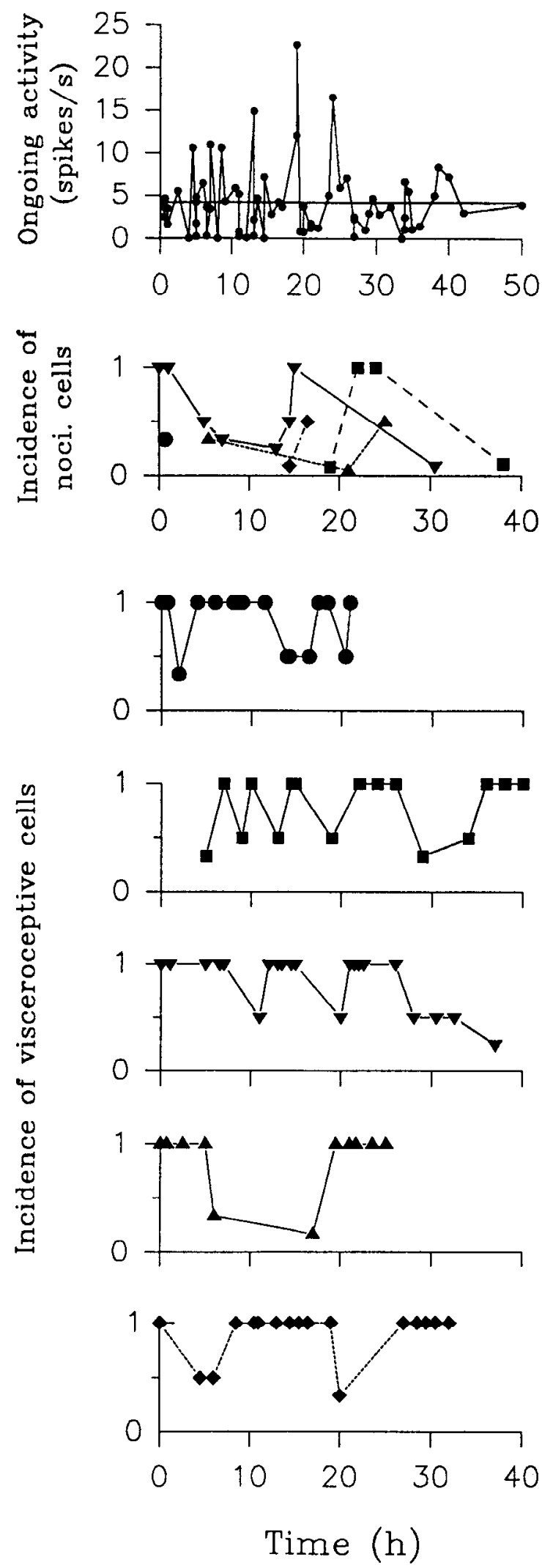

Figure 7. Lack of time trends in unit activity and responsiveness. $A$, Spontaneous activity of 66 neurons from five animals are plotted relative to the time at which the units were isolated (zero time $=$ first application of visceral stimulation). The regression line is shown, its slope was 0.0002 , and the intercept was $4.2=$ population spontaneous activity. The correlation coefficient for the slope was less than $0.001 . B$, Incidence of somatic nociceptive-responsive cells as a function of time. Incidence incidence of visceral responses and somatic nociceptive responses were examined. Randomly picked 66 cells from all five animals were used to examine the variation in spontaneous activity as a function of time (Fig. 7, top; zero time $=$ the first visceral stimulus in a particular experiment). The regression line through the data had a slope close to zero, implying that the spontaneous activity was constant over $50 \mathrm{hr}$ of recording. However, this slope was statistically nonsignificant due to the large variability in spontaneous activity between units. The mean ongoing activity of these neurons (as measured at the beginning of the characterization) was $4.2 \pm 4.2$ spikes/sec (range, $0-22.6$ spikes/sec; $n=66)$. The intercept of the regression line resulted in the same mean ongoing activity (Fig. 7, top).

The incidence of somatic nociceptive-responsive cells as a function of time, in each animal, is shown in Figure 7 (second graph). There is no obvious time-dependent trend in these data. The incidence of visceral-responsive cells as a function of time is shown separately for each animal in Figure 7 (bottom). Again, there are no obvious time trends in the data. Therefore, all three analyses show a lack of time dependent changes in unit activity and responses, implying a lack of sensitization and stable experimental conditions.

\section{Thresholds of visceral-responsive cells}

Thresholds were determined with increased intraluminal pressure for 60 cells (Fig. 8). This determination was done either with increasing steps or with a slow continuous increase of intraluminal pressure. The approximate accuracy is estimated to be $5 \mathrm{~mm} \mathrm{Hg}$ for pressures up to $40 \mathrm{~mm} \mathrm{Hg}$ and about $10 \mathrm{~mm}$ $\mathrm{Hg}$ for pressures higher than $60 \mathrm{~mm} \mathrm{Hg}$. The mean thresholds for units with urinary bladder inputs were $42.6 \pm 19.8 \mathrm{~mm} \mathrm{Hg}$ (mean $\pm \mathrm{SD}$; range, $19-80 \mathrm{~mm} \mathrm{Hg} ; n=13$ ) for excitatory responses and $34.7 \pm 13.8$ (range, $7-70 \mathrm{~mm} \mathrm{Hg} ; n=20$ ) for inhibitory responses. The mean thresholds for units with colon inputs were $37.0 \pm 14.9 \mathrm{~mm} \mathrm{Hg}$ (range, $16-70 \mathrm{~mm} \mathrm{Hg} ; n=9$ ) for excitatory responses and $34.1 \pm 14.8 \mathrm{~mm} \mathrm{Hg}$ (range, 15-55 $\mathrm{mm} \mathrm{Hg} ; n=17$ ) for inhibitory responses. The mean thresholds for units with esophageal inputs were $26.1 \pm 10.4 \mathrm{~mm} \mathrm{Hg}$ (range, 13-47 mm Hg; $n=13$ ) for excitatory responses and $28.1 \pm$ $18.3 \mathrm{~mm} \mathrm{Hg}$ (range, $5-65 \mathrm{~mm} \mathrm{Hg} ; n=28$ ) for inhibitory responses. Thus, for all three visceral organs there were neurons with thresholds in the non-noxious as well as in the noxious range (see Table 1). The distributions of the thresholds for excitation and inhibition are shown in Figure 8. There was no statistical difference between the excitatory and inhibitory thresholds for a particular organ and between organs, except between bladder and esophagus regarding the thresholds for excitation ( $t$ test, $p=0.014$ ). The mean thresholds for excitatory responses from the bladder are higher than for responses from the esophagus.

\section{Stimulus-response curves of visceral-responsive cells}

Stimulus-response curves for neurons with excitatory and inhibitory inputs from the three viscera are shown in Figure 9.

was calculated at each time where a somatic nociceptive-responsive cells was isolated, defined as $1 /(1+$ number of somatic non-nociceptive cells encountered since the last nociceptive cell). Each symbol type represents a different animal. $C$, Incidence of visceroceptive cells as a function of time. Incidence was defined for visceroceptive cells in comparison to nonvisccroceptive cells as in $B$. Each plot represents cells from one animal. The symbol types correspond to those in $B$. 

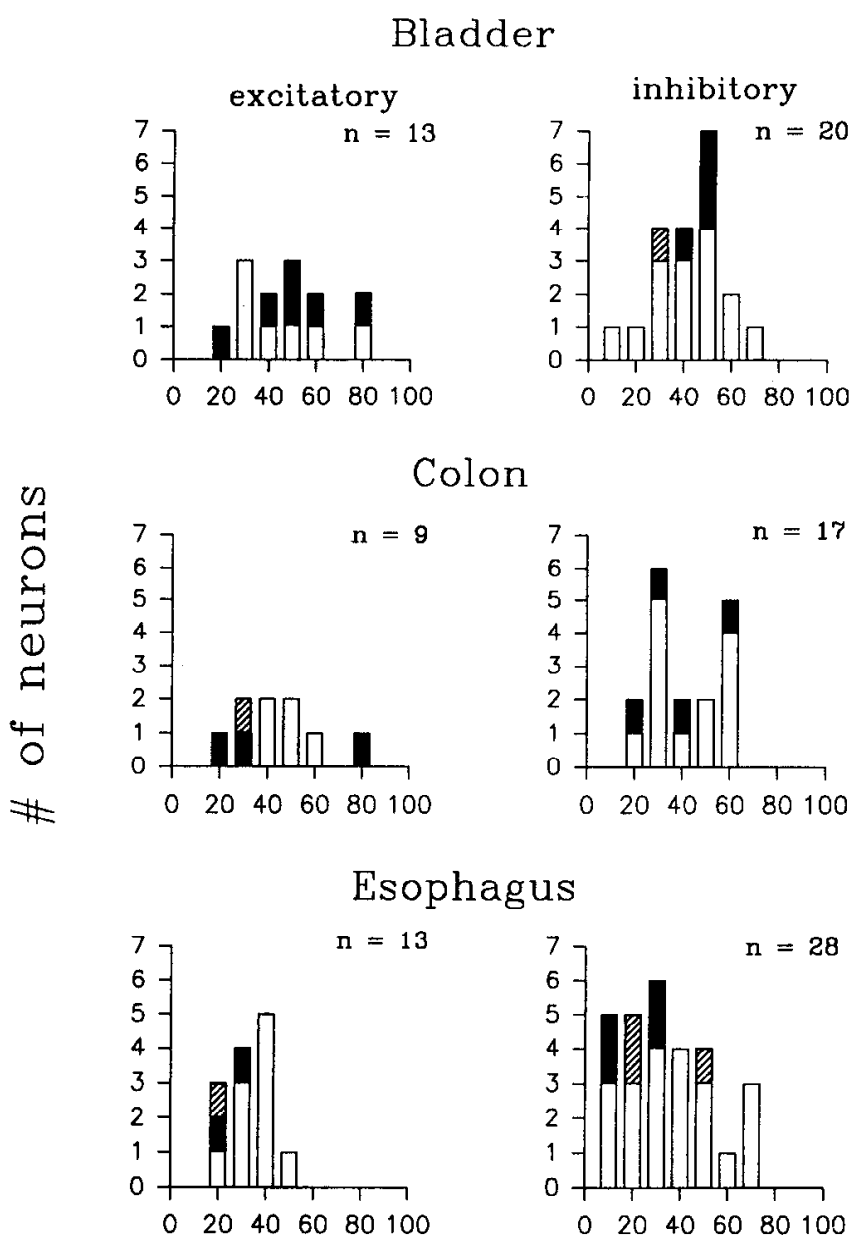

\section{Threshold ( $\mathrm{mmHg}$ )}

Figure 8. Thresholds for excitatory and inhibitory inputs from different visceral organs in classes of 0 to $<10,10$ to $<20 \mathrm{~mm} \mathrm{Hg}$, and so on. The open parts of the bars are the number of somatic low-threshold neurons, the solid parts are the number of somatic nociceptive neurons, and the hatched parts are the number of visceral-specific neurons.

Most individual neurons encoded increases in intraluminal pressures in a graded manner with either an increase or a decrease in firing rate. However, in the populations with excitatory responses there are cells with nonmonotonic stimulus response curves. The population stimulus response was approximated by a linear regression for all the neurons in each category. These regression lines show that both the rate of change (slope) and the spontaneous activity (intercept) are very similar across the viscera and response types (excitation or inhibition). The stimulus response curves for excitatory responses from esophagus stimulation had the largest variability $(r=0.18)$.

\section{Categories of visceroceptive cells}

The neuronal responses to visceral stimulation were subdivided into LTv, NSv, and WDRv. Two responses were LTv type. The ratio of WDRv to NSv responses was 2:30 for units with bladder inputs, 11:15 for units with colon inputs, and 22:18 for units with esophagus inputs. This $2 \times 3$ contingency table is statistically significant $\left(\chi^{2}=17.76, p<0.0005\right)$. More responses with bladder inputs were NSv and more esophagus responses were
A Urinary bladder
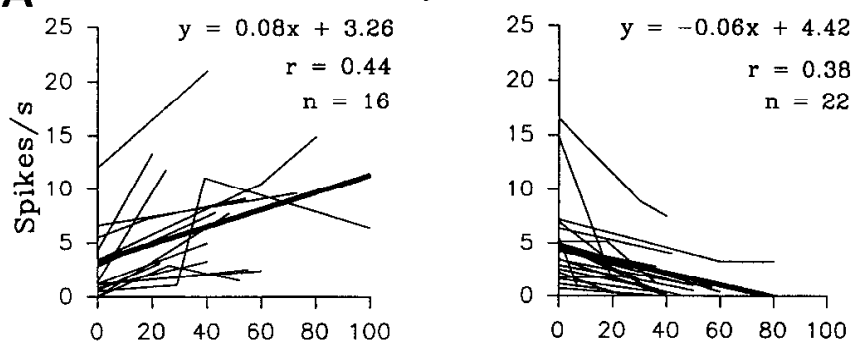

B

Colon
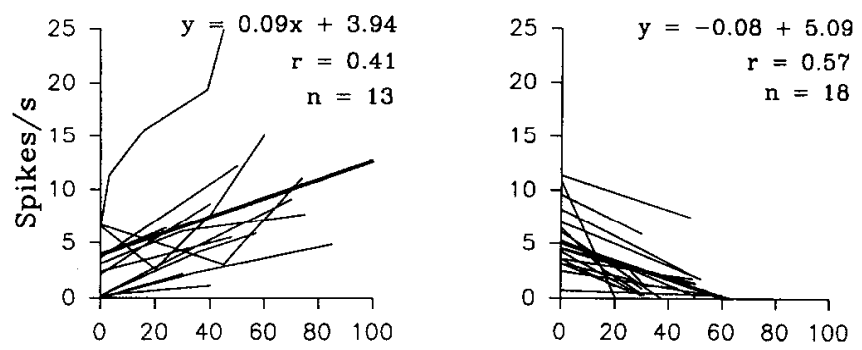

C

Esophagus
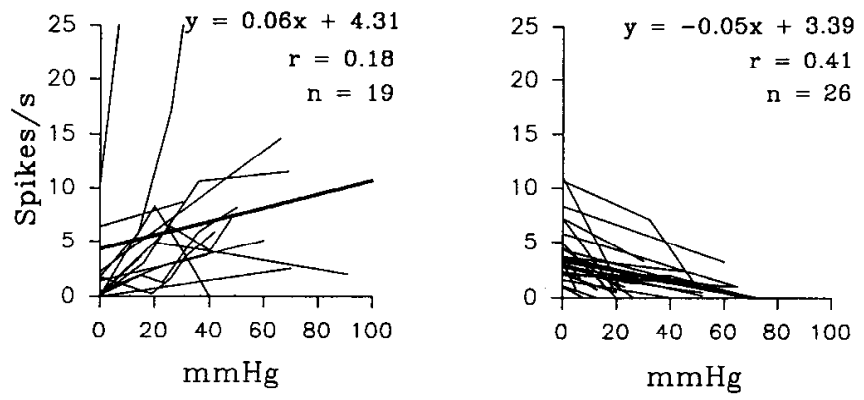

Figure 9. Stimulus-response curves of lateral thalamic neurons with excitatory and inhibitory inputs from the urinary bladder, the distal colon, and the lower esophagus. The thick lines represent the regression lines for each population. The values for each regression line are shown in the upper right of the graphs.

WDRv. Adding the responses to all three viscera, the incidences of NSv type responses were more common than the WDRv responses (63 vs 35 responses, respectively).

Figure 8 also subdivides the visceral response thresholds as a function of the somatic response types (LTs, NSs + WDRs, and visceral specific). The relationships between visceral and somatic nociceptive and non-nociceptive responses were compared. For units with esophagus inputs, the ratio of somatic nociceptive (NSs + WDRs) versus LTs cells was 0:17 when the responses to esophagus distension were NSv, and 6:14 when the esophagus responses were WDRv. This $2 \times 2$ contingency table was statistically significant (Fisher's exact, $p<0.02$ ), indicating a dependence between somatic and visceral response types for the esophagus inputs. All somatic LTs cells were also NSv type when they had esophageal inputs. The same relationship for the pelvic viscera was statistically non significant (bladder, 9:20 and $1: 2$; colon, $3: 12$ and 4:6, respectively)

Only two units with excitatory visceral inputs exhibited LTv responses: one unit increased its ongoing activity to esophagus distension only for pressures up to $20 \mathrm{~mm} \mathrm{Hg}$. The other unit increased its activity to bladder distension for pressures up to $28 \mathrm{~mm} \mathrm{Hg}$. Exclusively LTv response type cells were expected for the esophagus in the thalamus, since pure non-nociceptive 

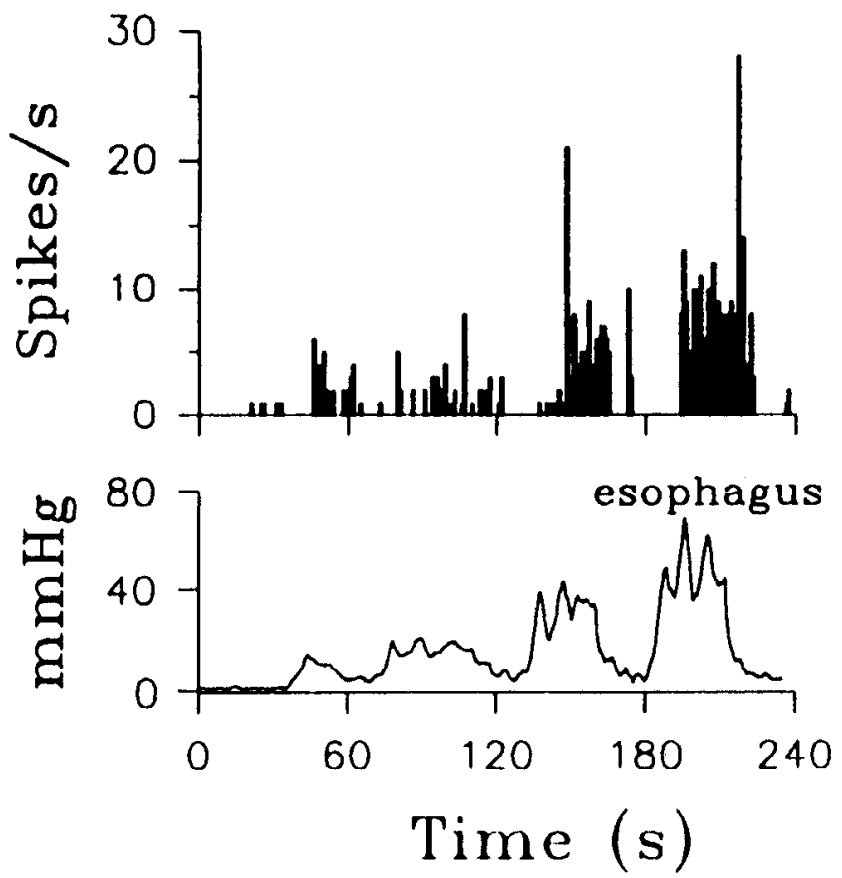

Figure 10. Peristimulus time histogram of graded responses of a visceral-specific VPL neuron to increasing intensities of esophagus distension. Bladder and colon distensions had no effect. The receptive fields of neighboring neurons were located on digits $2-4$ of the contralateral foot (see also Figure 9, cell 7). The trace below the graph shows the intraluminal pressure.

primary afferents have been described for the esophagus (Sengupta et al., 1989, 1990), but not for the pelvic viscera (see Jänig and Morrison, 1986). Although practically all primary pelvic afferents are of intensity coding type, many of the lateral thalamic neurons were of pelvic NSv type, especially the bladder responses.

\section{Visceral-specific cells}

The response of a visceral-specific neuron to esophagus distension is shown in Figure 10. This unit was not activated with distension of the colon or the bladder. Although most of the animal's cranial and postcranial skin, muscles, and joints were stimulated, no somatic receptive field could be found. This neuron encoded the duration as well as the intensity of esophagus distension accurately. It had a threshold of $9 \mathrm{~mm} \mathrm{Hg}$, and could code intraluminal pressures up to $70 \mathrm{~mm} \mathrm{Hg}$. Consequently, this neuron was classified as visceral-specific WDRv. It is striking to find such a visceral-specific, and probably organ-specific, neuron in the foot representation region of the main somatosensory nucleus of the thalamus (see also Fig. 12, cell 7).

Of the 106 neurons tested, six units were activated exclusively with visceral stimuli. Five of these cells were located in VPL and the other was found in VPM. Five were discovered when other neurons with a somatic receptive field were investigated and one was isolated based on its ongoing activity. The visceralspecific VPL neurons were located in the tail and foot representation area and the VPM unit was located in the vibrissae area. All six visceral-specific neurons responded to esophagus distension, but only one with excitation. Two of the six neurons responded each to colon (one excitation, one inhibition) and bladder distension (both were inhibited).

\begin{tabular}{lllll}
\hline Table 4. & \multicolumn{4}{l}{ Viscerovisceral convergence of lateral thalamic neurons } \\
Bladder & Colon & Esophagus & VPL & Other \\
\hline $\mathrm{X}$ & $\mathrm{X}$ & $\mathrm{X}$ & $15(32 \%)$ & $10(34 \%)$ \\
$\mathrm{X}$ & & $\mathrm{X}$ & $11(23 \%)$ & $6(21 \%)$ \\
& $\mathrm{X}$ & $\mathrm{X}$ & $6(13 \%)$ & $4(14 \%)$ \\
$\mathrm{X}$ & $\mathrm{X}$ & & $2(4 \%)$ & 0 \\
& & $\mathrm{X}$ & $11(23 \%)$ & $8(28 \%)$ \\
$\mathrm{X}$ & & & $2(4 \%)$ & $1(3 \%)$ \\
& $\mathrm{X}$ & & 0 & 0 \\
$47(62 \%)$ & $37(49 \%)$ & $71(93 \%)$ & $47(100 \%)$ & $29(100 \%)$
\end{tabular}

Seventy-six lateral thalamic neurons were tested for inputs from all three viscera. The number of cells and percentages exhibiting certain combinations of viscerovisceral convergence are indicated and grouped as within and outside VPL (Other). The bottom row shows the absolute and relative numbers of cells responding to each viscus and total numbers of cells tested inside and outside VPL.

\section{Visceral inputs of multivisceral-responsive neurons}

The majority of the cells with visceral inputs were responsive to more than one organ tested. Various combinations of different convergent visceral inputs were observed. Table 4 summarizes the extent of convergence between the three viscera for all the visceroceptive cells tested in the lateral thalamus $(n=76 ; 47$ inside VPL, and 29 outside VPL). The values in Table 4 include excitatory, inhibitory, and mixed responses. Seventy-one percent of all visceroceptive neurons had inputs from two or three visceral organs. The highest probability combination was convergent input from all three viscera (25 of 76 cells, $33 \%$ ). For the neurons responsive to only two viscera, the lowest probability was convergence between bladder and colon (4\%). Ninetythree percent of the visceroceptive neurons tested for input from all three viscera responded to esophagus distension. One-quarter of these responded exclusively to esophagus distension. Only 3 of $76(4 \%)$ neurons tested for input from all three viscera were uniquely responsive to urinary bladder input, and none received exclusive input from the colon, even though, due to the search strategy, mainly lateral thalamic regions with lower body somatic receptive fields were investigated. The degree of convergence between the three viscera was very similar for cells located inside of VPL as compared to those outside of VPL ( $\chi^{2}$ test, $p$ $>0.9$ ).

\section{Proper and improper viscerovisceral combinations}

The interrelation between the various inputs for cells with multivisceral responses are shown for two tracks in Figures 11 and 12. In Figure 11, units 10, 13, 14, and 16 (4 of $11,36 \%$ ) had proper, and units $5,6,12,17$, and 20 (5 of $11,45 \%)$ had improper viscerovisceral convergences in this track. In Figure 12, units 6 and 12 ( 2 of 14, 14\%) had proper, and 1, 3, 4, 9, 10, and 14 (6 of $14,43 \%$ ) had improper viscerovisceral convergences (mixed responses are ignored).

The ratios of proper to improper viscerovisceral interactions for all visceral responses were 4:5 for excitatory and 3:16 for inhibitory bladder responses; $3: 4$ for excitatory and $6: 13$ for inhibitory colon responses; and 6:5 for excitatory and 7:21 for inhibitory esophagus responses. $\chi^{2}$ test for the $3 \times 4$ contingency table showed no statistical difference between the three viscera $\left(\chi^{2}=1.79, p=0.94\right)$. Therefore, the responses to the three viscera were grouped. The $2 \times 2$ contingency table for the incidence of excitatory versus inhibitory responses and proper versus improper interactions was statistically significant (grouped 


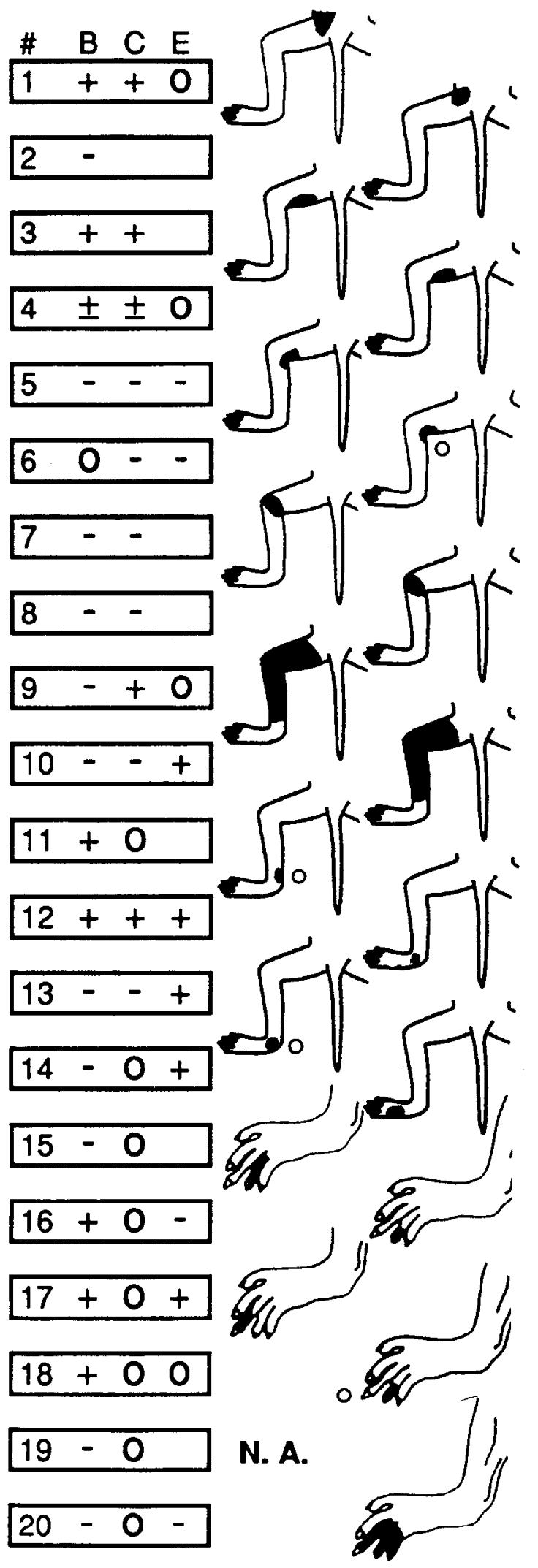

Figure 11. Reconstruction of an electrode penetration through the lateral VPL. Somatic nociceptive receptive fields are marked next to the receptive fields (open circles). All somatic responses were widedynamic-range type. 0 , no response; - , inhibition; + , excitation; \pm , mixed responses; due to distension of the urinary bladder $(B)$, colon (C), or lower esophagus (missing symbols, not testcd; N.A., somatic receptive field was not available).

\begin{tabular}{lcc}
\hline $\begin{array}{l}\text { Table 5. } \\
\text { neurons }\end{array}$ & Somatic response types of visceroceptive lateral thalamic \\
Somatic & VPL & Other \\
\hline None & 5 & 1 \\
LT & 43 & 18 \\
WDR & 10 & 5 \\
NS & 2 & 4 \\
Total & 60 & 28
\end{tabular}

NS, nociceptive specific type; LT, low-threshold type; None, no somatic receptive field, i.e., visceral specific; Other, cells outside VPL; WDR, wide-dynamic-range type.

excitatory responses had a proper to improper ratio of $13: 14$ and inhibitory responses a ratio of 16:50; Fisher's Exact, $p=$ 0.03 ). This comparison implies that the visceral excitatory responses more often had proper interactions than inhibitory responses.

For neurons where inputs from all three viscera were adequately characterized, altogether 56 neurons ( 20 neurons with mixed visceral responses were excluded from this analysis), 16 different combinations of excitatory, inhibitory, or no responses were observed, of a total of 26 (i.e., $3^{3}-1$ ) possible combinations. Assuming random sampling from 26 equiprobable triplets, the probability of 10 or more triplets not being observed in 56 observations is less than $1 \times 10^{-5}$ (upper bound combinatorial calculation; see Feller, 1956). The latter implies that the observed triplets are a special subset relevant to the task being performed.

The mean incidence of the 16 observed triplets was $3.5 \pm$ $3.34(n=56)$. Although the overall incidence seems randomly distributed, there were large incidence differences between the triplets. The most frequent triplet combination was exclusive inhibitory input from the esophagus ( 13 units, $23 \%$; i.e., a combination of 00 - inputs from bladder, colon, and esophagus stimuli, symbols according to Figs. 11, 12). The next most frequent triplets were inhibitory inputs from all three viscera (- - ; 13\%, improper interaction) and inhibitory inputs from the bladder and the esophagus $(-0-; 13 \%$, improper interaction), or colon and esophagus inputs $(0--; 9 \%$, improper interaction).

The dominant esophagcal input to the lateral thalamus is also reflected in the fact that in $27 \%$ of the observed viscerovisceral combinations were associated with excitatory esophageal input: these were either with no pelvic inputs $(11 \%)$, or in various combinations of convergent pelvic inputs $(16 \%)$. The two least represented categories (six triplets) were the antagonistic interactions between the pelvic viscera; only two such responses were seen.

\section{Response properties of somatovisceroceptive cells}

Somatic response properties. Of the 88 somatovisceral-responsive neurons studied, all but six (visceral specific) had welldefined somatic receptive fields. All the somatic receptive fields were contralateral to the thalamic recording side. The visceroceptive lateral thalamic neurons were assigned to four different classes according to their somatic response properties (Table 5). Most visccroceptive units $(61$ of $88,69 \%)$ were LTs type. Seventeen percent (10 of 60) of the VPL visceroceptive cells were somatic WDRs, and 3\% (2 of 60 ) were somatic nociceptive specific, that is, NSs type. The frequency of encountering LTs, 


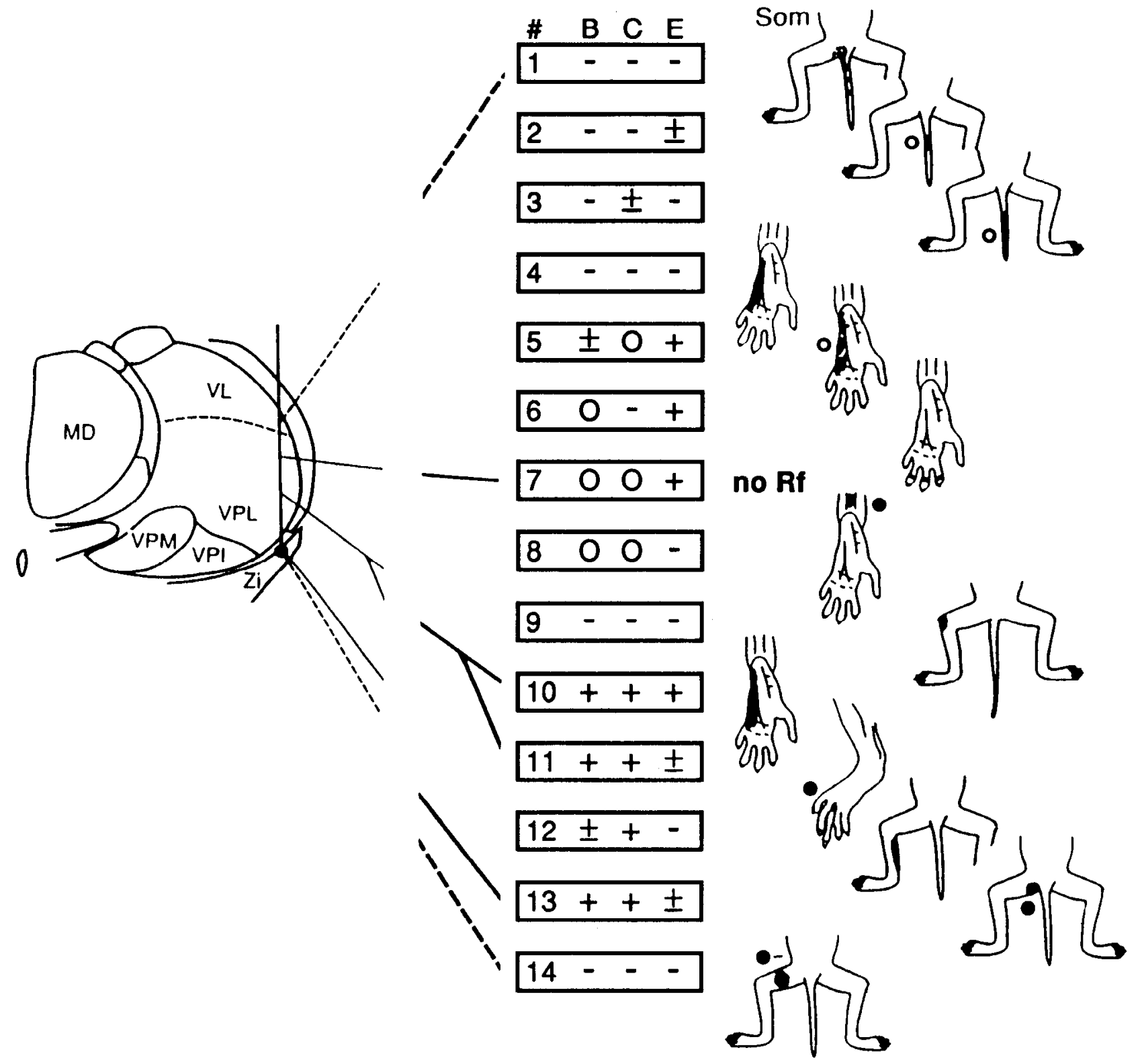

Figure 12. Reconstructed electrode penetration through a single frontal section of VPL. Recording sites, somatic receptive fields (wide-dynamicrange type marked with an open circles, nociceptive-specific type with solid circles; no $R F$, no somatic receptive field found), and visceral inputs $(B$, bladder input; $C$, colon input; $E$, esophagus input; +, excitation; - , inhibition; $\theta$, no response; \pm , mixed responses) are shown. The most dorsal neuron was located in VL and the two most ventral ones were in ZI (location marked with a lesion; indicated as a solid circle in the figurine). Abbreviations for the thalamic nuclei: $M D$, medial dorsal nucleus; $V L$, ventrolateral nucleus; $V P I$, ventral posterior inferior nucleus; $V P L$, ventral posterior lateral nucleus; $V P M$, ventral posterior medial nucleus; $Z i$, zona incerta.

WDRs, and NSs type cells in VPL is similar to our findings in the preceding companion article (Apkarian and Shi, 1994). The neurons in ZI are noteworthy, since all three were nociceptive: two were NSs type, and one was WDRs type. We have seen ZI neurons with similar viscerosomatic response properties in the cat (Brüggemann et al., in press).

Visceral response properties. The relation between visceral response types (LTv, WDRv, and NSv) and convergent somatic responses (LTs, WDRs, and NSs) was compared for excitatory and inhibitory visceral inputs. For the 19 units with WDRv excitatory responses, the ratio of LTs to nociceptive responses (WDRs + NSs) was 15:4; and for WDRv inhibitory responses this ratio was $24: 9$. For units with NSv excitatory responses this ratio was 9:4, and for NSv with inhibitory responses this ratio was 21:5. Fisher's exact test shows no statistical significance for both visceral excitatory and inhibitory inputs, implying that the probability of encountering somatic non-nociceptive or nociceptive responses is not predictable from the visceral inputs. Fifteen units with excitatory WDRv and nine units with excitatory NSv responses had convergent LTs inputs.

Dorsoventral ordering of the somatic receptive fields. The somatic receptive fields of the visceroceptive cells in VPL had a precise somatotopy. The somatic nocircsponsive cells seemed randomly scattered in between LTs type cells, and the body map was identical to that described by others (Kaas et al., 1984; see Apkarian and Shi, 1994). In Figures 11 and 12 two reconstruc- 

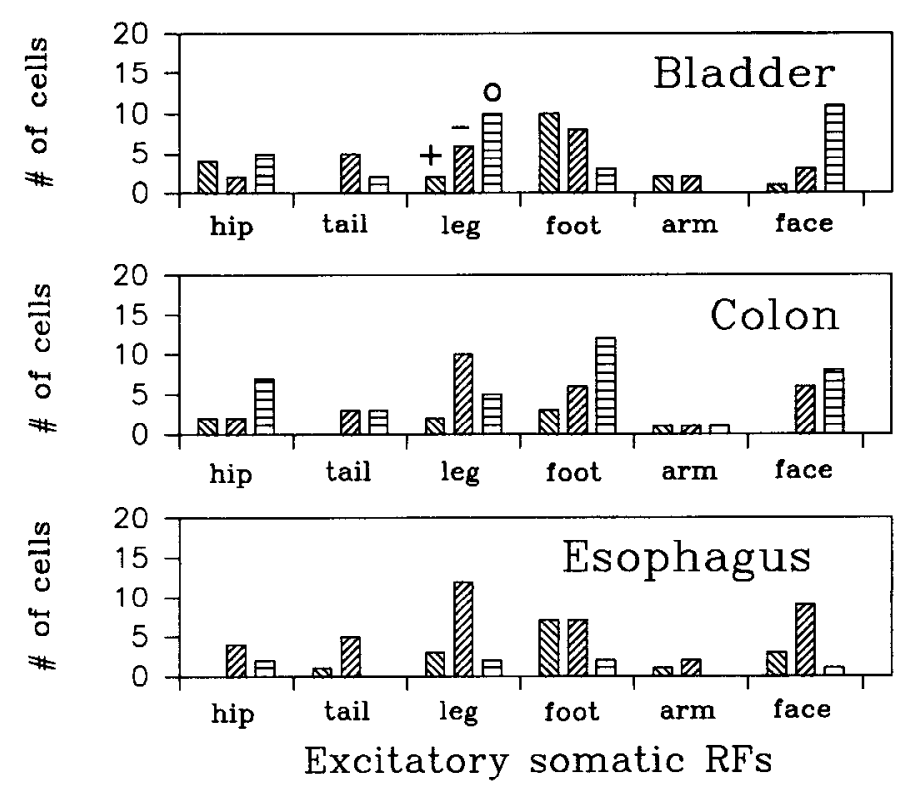

Figure 13. Somatovisceral convergence in the lateral thalamus. Only neurons with excitatory somatic inputs are considered in this table. According to the location of the somatic receptive fields, these were divided into six categories: hip region (includes lower back, perianal, and suprapubic regions), tail, leg, foot, arm, and face ( + , excitatory; -, inhibitory; 0 , no response to visceral stimulation).

tions of electrode tracts through comparable regions of the lateral VPL and the somatic and visceral receptive fields of the units isolated in these tracks are shown. The responses and receptive fields of the 20 units are illustrated in Figure 11. Dorsally in VPL, the somatic receptive fields were located on the hip skin. More ventrally the somatic receptive fields progressed from proximal to distal body parts. The ventralmost five units had receptive fields on the digits of the contralateral foot. Four of the units in this track had WDRs type responses.

In Figure 12 (14 units), dorsally the somatic receptive fields were on the tail (the first unit was in VL). Deeper, in VPL the somatic receptive fields jumped to the lateral foot, and more ventrally the last somatic receptive field (unit 11) was located on the proximal joint of digit 3 and had an NSs response. Unit 12 was the most ventrally located neuron in VPL, which responded to brushing the ankle and innocuous probing of the gastrocnemius muscle. Units 13 and 14 were located in ZI (marked by an electrolytic lesion). Unit 13 had excitatory responses to deep noxious squeezing of the hip muscle, while unit 14 was inhibited by noxious pinching of the proximal hindlimb. No somatic receptive field was found for unit 7 . The frequency of somatic nociceptive neurons in this track was unusually high.

Examples of somatovisceral convergence. The somatovisceral convergence and the relation between the somatic and visceral receptive fields was examined in 88 neurons. Figures 11 and 12 show the correspondence between the visceral and somatic receptive fields in two tracks. In Figure 11, with bladder stimulation units $1,3,13,14,15$, and 20 have proper somatovisceral interactions ( 6 of $19,32 \%$ ); while units $11,12,16,17$, and 18 have improper somatovisceral interactions ( 5 of $19,26 \%)$, the other responses cannot be classified. With colon stimulation units $1,3,9$, and 13 have proper somatovisceral interactions (4 of $11,36 \%$ ), while unit 12 has an improper interaction ( 1 of 11 , $9 \%$ ). With esophagus stimulation, units 5, 6, 16, and 20 have proper ( 4 of $9,44 \%$ ), while units $10,12,13,14$, and 17 have improper somatovisceral interactions ( 5 of $9,55 \%$ ). In Figure 12 ( $n=14$ units), with bladder stimulation unit 13 has proper $(7 \%)$, and units 10 and 11 have improper somatovisceral interactions (14\%), while with colon stimulation units 12 and 13 have proper (14\%), and units 10 and 11 have improper somatovisceral interactions (14\%); with esophagus stimulation units $1,3,4,8,9,12$, and 14 have proper $(50 \%)$ and units 5,6 , and 10 have improper somatovisceral interactions (21\%).

Units 9 and 10 in Figure 11 were recorded simultaneously at the same site and were discriminated by spikc amplitude. Their somatic receptive fields were similar and covered most of the leg. However, their visceral inputs were distinct. Unit 10 had inhibitory responses to distension of the bladder and the colon and excitatory responses to esophagus distension, while the unit nearby was inhibited with bladder distension, and had excitatory input from the colon, but was nonresponsive to esophagus stimulation. The somatic receptive field of unit 10 included proper dermatomes for the pelvic viscera, but improper ones for the esophagus. Thus, although the somatovisceral convergence regarding the esophagus was improper, the viscerovisceral convergence was classified as proper. A comparable observation was made for units 16 and 17 . Unit 17 had improper viscerovisceral interactions and improper somatovisceral interaction for both esophagus and for bladder stimulation. Unit 16 was recorded at the same site in VPL and was distinguished from unit 17 by spike amplitude. Its somatic receptive field was distinct from unit 17 and it had inhibitory responses to esophagus distension, which were classified as proper somatovisceral and proper viscerovisceral interactions. These examples show that VPL neurons, located very close to each other, could have distinct visceral input patterns, although their somatic responses followed the known somatotopical arrangement in VPL.

Proper and improper sornatovisceral combinations. Figure 13 summarizes the somatovisceral interactions for all the units with excitatory somatic receptive fields. For the data shown in this figure, we assume conservatively that bladder and colon proper somatic receptive fields include the hip regions (this contains excitatory somatic receptive fields on the lower back, perianal, and suprapubic regions), the tail, and the upper and lower leg. Excitatory bladder and esophagus responses were most frequent when the somatic receptive fields were on the foot (10 of 21 and 7 of 16 units, respectively), both are improper somatovisceral interactions. Inhibitory esophagus responses were most common when the somatic receptive fields were on the leg (12 of 17), which are proper somatovisceral interactions. An extreme example of improper interactions between somatic and visceral inputs is the unit with excitatory bladder input and an excitatory somatic receptive field on the face.

The ratios of proper to improper somatovisceral interactions for all visceral responses were 6:13 for excitatory bladder responses, 4:4 for excitatory colon responses, and 1:11 for excitatory esophagus responses. For inhibitory responses from the pelvic organs only proper interactions could be determined, which were 13 for bladder inhibitory responses and 13 for colon inhibitory responses. For inhibitory responses from the esophagus the ratio of proper to improper interactions was 37:2. Dropping the esophagus inhibitory improper inputs, a $3 \times 3$ contingency table is generated for excitatory proper and improper somatovisceral interactions and inhibitory proper interaction categories as a function of the three viscera stimulated. This table is statistically significant $\left(\chi^{2}=13.5, p=0.009\right)$. Post hoc 


\begin{tabular}{|c|c|c|}
\hline $\begin{array}{l}\text { Track } \\
\#\end{array}$ & Sequence of responses & $\mathrm{C}$ \\
\hline \multicolumn{3}{|c|}{ Bladder } \\
\hline 1 & $+-+ \pm-0----++---+++--$ & 0.90 \\
\hline 2 & $---- \pm 000-++ \pm+-$ & 0.89 \\
\hline 3 & 000000 & 0.76 \\
\hline 4 & $0000++$ & 0.67 \\
\hline 5 & $000+00$ & 0.93 \\
\hline 6 & ----+ & 0.80 \\
\hline 7 & 00000 & 0.66 \\
\hline 8 & $000++$ & 0.72 \\
\hline 9 & $-0-+$ & \\
\hline 10 & 0000 & \\
\hline 11 & +00 & \\
\hline 12 & - \pm \pm & \\
\hline \multicolumn{3}{|l|}{ Colon } \\
\hline 1 & $++ \pm----+-0+-0000000$ & 0.87 \\
\hline 2 & $-- \pm-0-00-++++-$ & 0.93 \\
\hline 3 & $-+00-- \pm$ & 0.86 \\
\hline 4 & \pm \pm 00 & 0.75 \\
\hline 5 & --++ & 0.75 \\
\hline 6 & 000000 & 0.76 \\
\hline 7 & 00000 & 0.66 \\
\hline 8 & $00++$ & 0.72 \\
\hline 9 & 0000 & \\
\hline 10 & $0+-0$ & \\
\hline 11 & 000 & \\
\hline 12 & $-0-$ & \\
\hline
\end{tabular}

\section{Esophagus}

\begin{tabular}{rll}
1 & $00--0++++-+0-$ & 0.85 \\
2 & - \pm--+++--+ \pm- \pm- & 0.83 \\
3 & - \pm----- & 0.76 \\
4 & - \pm & 1.00 \\
5 & ----+ & 0.80 \\
6 & $0+----$ & 0.83 \\
7 & ----- & 0.66 \\
8 & -++++ & 0.80 \\
\hline 9 & ---+ & \\
10 & --++ & \\
11 & ++ & \\
12 & $0-$ & \\
\hline
\end{tabular}

\begin{tabular}{cll}
\hline Somatic & & \\
1 & +++++++++++++++++ & 0.47 \\
2 & $++++++0++++++-$ & 0.65 \\
3 & $+++0+++$ & 0.88 \\
4 & ++++++ & 0.76 \\
5 & +++++ & 0.66 \\
6 & ++++++ & 0.76 \\
7 & +++++ & 0.66 \\
8 & $+0++$ & 0.80 \\
9 & ++++ & \\
10 & $+0++$ & \\
11 & $+0+$ & \\
12 & +++ &
\end{tabular}

The scquences of symbols ( + , excitation; - , inhibition; 0 , no response; and $\perp$, mixed response) represent response types of visceroceptive neurons observed in analysis shows no statistical difference between proper and improper somatic interactions as a function of inputs from the three viscera. However, a significant difference is found between excitatory and inhibitory responses as a function of the inputs from the 3 viscera $\left(\chi^{2}=9.7, p=0.008\right)$. For esophagus stimulation, the $2 \times 2$ contingency table of proper versus improper somatovisceral interactions and excitatory versus inhibitory visceral responses is highly significant (Fisher's Exact, $p<0.001$ ). This implies that esophagus excitatory responses had mainly improper, while inhibitory responses had mainly proper interactions. This highly significant esophageal-somatic interaction is the major factor giving rise to statistical significance in the above viscerosomatic convergence tables.

The above numbers include the responses of somatic nociceptive as well as somatic non-nociceptive neurons with visceral input. Grouping the responses with respect to somatic nociceptive or somatic non-nociceptive inputs, the following proper to improper interaction ratios were observed. For somatic nociceptive neurons the ratio was 3:4 for bladder responses, $2: 2$ for colon responses, and 7:4 for esophagus responses. For somatic non-nociceptive neurons the ratios was $16: 9$ for bladder responses, 15:2 for colon responses and 32:11 for esophagus responses. The $2 \times 2$ contingency tables of proper to improper interactions as a function of somatic nociceptive to non-nociceptive responses for each viscus, and for all viscera together, were statistically nonsignificant (Fisher's Exact or $\chi^{2}$ tests). This implies that the viscerosomatic convergence pattern is similar between cells with somatic nociceptive and non-nociceptive inputs.

\section{Grammar complexity measures}

Normalized context free grammar complexity was measured in two ways: first, each dorsoventral sequence of responses in each track was regarded as a word consisting of the four symbols $(+$, $-, 0, \pm$ ) for each viscus, and for the somatic responses (see Table 6). Due to the limited numbers of neurons in some penetrations, this was done for the first eight tracks shown in Table 6. Second, all sequences of responses of all 12 tracks in Table 6 were added up for each organ and for somatic inputs, thus creating four large words. Maximum grammar complexity (1.00) corresponds to a random sequence of letters, or to the maximum amount of information transmitted. The minimum complexity $(0.00)$ is equivalent to no transmission of information, or to repeatedly transmitting the same message for infinite time.

The two tracks with the largest number of isolated cells are those shown in Figures 11 and 12. Taking the first eight tracks of Table 6 into account, the mean grammar complexity for single words was $0.70 \pm 0.10$ (mean $\pm \mathrm{SD}$ ) for bladder stimulation, $0.70 \pm 0.09$ for colon stimulation, $0.73 \pm 0.10$ for esophagus stimulation, and $0.65 \pm 0.20$ for the somatic responses. Repeated-measures ANOVA showed no significant difference between the four groups.

Using the sequences of all 12 tracks as a single word for each organ and for somatic responses, the calculated grammar complexities were 0.68 for bladder, 0.63 for colon, 0.64 for esophagus, and 0.35 for somatic responses. This metric was equal for all visceral responses, implying equal random representation for

$\longleftarrow$

dorsoventral tracks through the primate lateral thalamus. The normalized value for complexity (C) is shown in the right column for the first eight tracks of each section. 
all three inputs. Grammar complexity for the somatic responses was the lowest, because most somatic responses were excitatory.

Response properties of somatic-specific cells

For 16 of the $106(16 \%)$ lateral thalamic neurons tested no visceral inputs were found. Since only three viscera were stimulated, possible visceral inputs from other organs, like, for example, the gall bladder, the kidneys, and so on, cannot be excluded. Of the 16 neurons, $13(81 \%)$ were LTs and three were WDRs (19\%). Five of these neurons were located inside VPL. The remaining 11 units were not unequivocally assignable to VPL or other thalamic nuclei. Like the visceral-specific neurons, these units were intermingled with the somatovisceroceptive and visceral-specific neurons and no segregation was found. The incidence of non-nociceptive versus nociceptive neurons are in agreement with the data found for the somatovisceroceptive neurons described in this study, and are in agreement with the previous investigation (Apkarian and Shi, 1994).

\section{Discussion}

The lateral thalamic visceroceptive neurons are most likely the same population of cells studied in the previous article and by others for somatic inputs (Kaas et al., 1984; Chung et al., 1986). The results of this study show the following. (1) The majority of lateral thalamic somatosensory neurons receive somatovisceral $(85 \%)$ and viscerovisceral $(71 \%$ of the $85 \%)$ convergent inputs from naturally stimulated visceral organs. Visceroceptive cells are found in many lateral thalamic nuclei: VPL, VPM, VPI, VL, ZI, PO, R, and Pulo. (2) Visceral response types were excitatory, inhibitory, and mixed. The thresholds for visceral activation and the responses to graded stimuli subdivided these cells into NSv and WDRv types, with an incidence ratio of 2:1 between the two types. Only two units had LTv type responses. The majority of these neurons were able to code visceral stimulus duration and intensity. (3) Most neurons responded to multiple visceral organs. The most common viscerovisceral combination was convergent input from all three viscera tested. For all three viscera, excitatory responses more often had proper interactions than inhibitory responses. Only a subpopulation of the 26 possible viscerovisceral input combinations were observed. (4) Six neurons responded exclusively to visceral distension and were classified as visceral-specific cells. (5) In general, the somatic receptive field locations of the visceroceptive neurons were not predictive of which visceral organs the units had inputs from, and also wcre not predictive of the response types from any given viscus, contradicting working hypotheses 1 (viscerotopy) and 2 (somatic and visceral coregistered topography). Consistent with hypothesis 2 , the esophageal inputs resulted mostly in inhibitory responses and had proper somatovisceral convergence. However the esophageal excitatory inputs had mostly improper somatovisceral convergence, contradicting hypothesis 1 and 2. (6) The somatic response properties (LTs vs WDRs + NSs) also were not predictive of the visceral response properties (WDRv vs NSv), contradicting our working hypothesis 3 (somatic and visceral corresponding response types). (7) Grammar complexity, when measured using all tracks together, was equal across all three visceral inputs and was higher than that measured for somatic inputs.

\section{Technical considerations}

We refer to the visceral stimuli used as "natural." The distension rates used for esophagus and colon stimulation are close to the rates that are experienced by humans in everyday life. The bladder distension rates are higher than normal, but these rates are used routinely in clinical urodynamic studies (Torrens and Morrison, 1987).

The intraluminal pressures used ranged from the innocuous to the presumably noxious range. However, the exact intensities delimiting non-nociceptive from nociceptive perceptions from these viscera are unclear and are reported within a wide range (for references, see Jänig and Morrison, 1986). This renders our groupings of WDRv and NSv responses rather imprecise.

A criterion suggested for distinguishing between visceral innocuous and noxious stimuli is a transient change in blood pressure (e.g., Cervero, 1983). We continuously monitored blood pressure and heart rate in these experiments. However, changes in blond pressure were small (generally below $10 \mathrm{~mm} \mathrm{Hg}$ ) and not consistently related to the pelvic visceral stimuli. Esophagus distension frequently elicited small, transient decreases in blood pressure. Generally, these changes in blood pressure were regarded too small to activate baroreceptive thalamic neurons. However, it is possible that some of the visceral responses that were accompanied with larger blood pressure changes were partially in response to activation of baroreceptors.

We find a larger than expected representation of viscera in the lateral thalamus. This may be interpreted as due to some sort of unmasking of silent synapses as a result of the animals' state during the recordings. However, a number of observations do not support this interpretation. The constancy of the spontaneous neuronal discharge rates over a $50 \mathrm{hr}$ time period, and the constancy of the incidence of various cell types are also indications for stable experimental conditions. The appropriateness of the anesthesia is evident in that none of the cells studied had somatic receptive fields extending to the ipsilateral body and the sequence of somatic receptive fields in a given track was identical to earlier studies. In addition, electrophysiological studies in the awake monkey show comparable ratios of nociceptive versus non-nociceptive neurons in VPL (see preceding companion article, Apkarian and Shi, 1994).

\section{Comparison with earlier thalamic visceral physiology}

The present study is the second physiologic study of thalamic visceral representation in the monkey. Chandler et al. (1992) reported the first study of visceral representation in the macaque lateral thalamus. Somatic nociceptive units were isolated in VPL and their responses to noxious distension of the urinary bladder was tested. Altogether 31 bladder-responsive cells were found (22 excited and 9 inhibited, in 21 animals). These neurons were all located within the core of VPL and some could be backfired from the somatosensory cortex. They conclude that all three of our working hypotheses (viscerotopy, somatic, and visceral coregistered topography and correspondence in response types) hold in the macaque lateral thalamus. Thus, the results of Chandler et al. (1992) appear to be contradictory to the present study. We think that the differences between the two studies are mostly due to differences in the search strategies. The probability of encountering neurons with somatic nociceptive inputs from the lower body and convergent excitatory inputs from the urinary bladder was similar in both studies ( 22 cells in 21 animals by Chandler et al., and five cells in five animals here). The ratio of neurons with excitatory bladder input and upper or lower body somatic receptive fields (2:19 in Chandler et al., 3:16 in our study) and the relation betwecn bladder stimulation effects and the somatic response types was also similar in both studies. 
Modern physiologic studies show that visceroceptive cells in the cat lateral thalamus generally are not found in the core of VPL or VPM. In the cat lateral thalamus, Brüggemann et al. (1993) report that all neurons with visceral inputs are of somatic LT type and are located either in the periphery of VPL or in the adjacent $\mathrm{PO}$, while Yokota and colleagues report that the visceroceptive cells receive somatic nociceptive inputs are located in the periphery of VPL but not in the adjacent PO (Taguchi et al., 1987; Asato and Yokota, 1989). Despite these inconsistencies between laboratories, it should be clear that the visceral representation seen in the cat lateral thalamus is very different from our results for the monkey lateral thalamus.

Recent studies by Berkley et al. (1993b) demonstrate visceroceptive neurons in and around the rat VPL, tested by stimulating the reproductive organs and the colon in female rats. Neurons with different degrees of viscerovisceral convergence were found in different regions of the lateral thalamus. We did not observe such segregation of visceroceptive cells in the squirrel monkey lateral thalamus, and all of our visceral-specific cells were in VPL or VPM. Berkley et al. also report an increased incidence of somatic nociceptive responses for cells with visceral inputs. We did not observe such differences in the monkey. Therefore, the results of the studies that have examined visceroceptive neurons in the mammalian lateral thalamus suggest important differences between species.

\section{Viscerotopy versus nonviscerotopy}

Our results show an overall lack of viscerotopy in the monkey lateral thalamus, in agreement with Berkley et al. (1993b). However, we cannot rule out a crude topography that might become evident only statistically after studying a much larger population of neurons in this region. In the rat, $22 \%$ of lateral thalamic cells with visceral inputs from the pelvic space had somatic receptive fields from the upper body region, including the face (Berkley et al., 1993b). The latter is in agreement with the existence of a large number of improper somatovisceral interactions in the squirrel monkey lateral thalamus.

One study in the rat (Cechetto and Saper, 1987) shows viscerotopic organization at levels above the brainstem. They demonstrated that rostral parts of the insular cortex contain neurons with taste input and receive projections from VPMpc (analogous to $\mathrm{VMb}$, thought to be a relay region for taste), and that more caudal parts of the insula have other visceral inputs and are connected to a comparable region ventral to VPL, termed VPLpc by the authors (analogous to VPI). They report minimal viscerovisceral convergence in this part of cortex. This thalamoinsular connectivity completely avoided VPL and VPM. In the monkey the insular inputs are from VPI, VMb, and the PO (Mufson and Mesulam, 1984; Akbarian et al., 1992). Extrapolating from the rat results, we would conclude that some of these thalamic areas may exhibit a topographic visceral organization.

In the rat and cat spinal cord it has becn demonstrated that each viscus is dominantly represented within one or two segments. Also, it is shown in the monkey that most spinothalamic cells located in the segments of termination of visceral afferents exhibit excitatory responses to visceral stimulation of the organs concerned (Milne et al., 1983). Therefore, the majority of the spinal cord physiology indicates that these cells are organized viscerotopically. However, recent studies in the rat indicate the existence of spinal cord cells with large somatic receptive fields (Berkley et al., 1993a) and responses from remote viscera (Gebhart, personal communication). Since our data, and those in the rat (Berkley et al., 1993b), show that VPL lacks a viscerotopy, visceral inputs to VPL must include pathways originating outside of the tracts originating in the spinal cord, for example, the dorsal column pathway.

\section{Distribution of visceral response categories}

We show that visceral-responsive cells were mostly nociceptive, and two-thirds were NSv type while one-third were WDRv type. This distribution between NSv and WDRv is very different from what has been reported for the spinal cord and the peripheral afferents, where, with our nomenclature, the majority of the visceral responses would be of WDRv type (Milne et al., 1981; McMahon and Morrison, 1982a,b; Bahns et al., 1986, 1987; Sengupta et al., 1989, 1990). We also show that the responses to bladder stimulation were more often NSv type, while the responses to esophagus stimulation were more often WDRv type. Again, these distributions are opposite of what generally has been reported for spinal cord neurons. Moreover, all thalamic esophagus NSv-responsive units had LT somatic responses. The correspondence between somatic response types and esophageal inputs remains unknown in the spinal cord. Overall, therefore, we conclude that the incidence of visceral response types and their relation to the somatic response types are different between the lateral thalamus and the spinal cord, implying thalamic visceral inputs from sources other than the spinal cord, and perhaps also preferential spinal cord projections.

\section{Visceral-responsive cells with low-threshold somatic inputs}

Our results show that $69 \%$ of the monkey visceroceptive lateral thalamic neurons are LTs type. Similarly, $56 \%$ of the visceroceptive lateral thalamic cells are reported somatic LT type in the rat (Berkley et al., 1993b). In contrast, in the monkey spinothalamic tract only $0-13 \%$ of the somatovisceral spinal cord ncurons are classified as somatic LT type, while $63-76 \%$ are classified as somatic WDR type, and $13-42 \%$ as somatic NS type (Foreman et al., 1981; Milne et al., 1981; Ammons et al., 1985; Brennan et al., 1989). Other spinal cord ascending pathways also have a small population of somatic LT type cells and can transmit visceral information, including the spinoreticular (Foreman et al., 1984; Hobbs et al., 1990), and the spinomesencephalic tracts (Yezierski and Broton, 1991).

Visceral inputs can be conveyed to the thalamus through the dorsal column, medial lemniscal pathway (Yamamoto et al., 1956; Rigamonti and Hancock, 1974, 1978; Kuo and de Groat, 1985). In a preliminary report Hubscher and Berkley (1992) show that $50 \%$ of cells in the rat dorsal column nuclei respond by excitation or inhibition to stimulation of the uterus, vagina, or cervix; $22 \%$ of these cells responded to more than one viscus, and $95.5 \%$ had somatic responses to brushing. Many of these somatic receptive fields were located on upper body parts (improper somatovisceral convergence). This report provides the most compelling evidence regarding a source for VPL somatic low-threshold cells with diverse visceral inputs. Since the dorsal column pathway provides the primary low-threshold input to the lateral thalamus, and since most cells in the dorsal column nuclei seem to receive visceral inputs (with many improper somatovisceral convergent inputs), we conclude that the major source of the visceral responses that we have seen in the squirrel monkey thalamus must be through direct lemniscal thalamic inputs. These inputs, however, do not rule out a vagothalamic 
input that might also provide visceral inputs on somatic lowthreshold type cells.

\section{Visceral-specific cells}

In the present study 6 of $60(10 \%)$ neurons were classified as visceral specific. Berkley et al. (1993b) report that, in the rat, $26 \%$ of the neurons, tested with uterus, cervix, vagina, and colon stimulation, had visceral-specific responses. However, the location of the visceral-specific cells in the lateral thalamus seem different between rat and monkey (see above). Our results are in agreement with the small number of visceral-specific spinal neurons reported by Rucker et al. (1984). In general, visceralspecific units in significant numbers have not been described in the spinal cord. It is likely that there is a visceral-specific projection to the thalamus from the brainstem, which may be larger in the rat than in the monkey (see Cechetto and Saper, 1987).

\section{Grammar complexity as a measure of information processing}

Grammar complexity as defined here is a relative measure of regularity versus randomness in a given sequence of symbols. The authors who introduced this measure state that "an absolute complexity measure for finite sequences is, we think, nonexistent" (Jiménez-Montaño, 1984). Here, we use grammar complexity as a measure of the information transmitted by one input in comparison to the others, when the direction of the response $(0,+,-, \pm)$ is the code. Obviously, the approach is simplistic, since the representational code was reduced to a quaternary code.

The grammar complexity comparison between the organs showed no statistical difference. This is partially due to the short sequence of elements that constitutes each word. As a result, we had to combine these fragments into one large word, in which case there were differences between visceral and somatic responses. For the somatic responses grammar complexity was 0.35 , which approximately corresponds to having a continuous sequence of 64 repetitions of the same symbol embedded in a word of 80 letters. For the viscera complexity was about 0.65 , which corresponds to having a 64 element repeated sequence embedded in a 148 letter word. The fact that grammar complexity was lowest for the somatic responses simply affirms the validity of the procedure; that is, most somatic responses were repetitions of the same letter $(+)$. On the other hand, the similarity of grammar complexity for all three viscera implies that the representational pattern is similar for all three organs in the lateral thalamus.

\section{Coding versus modulation}

The majority of the visceral responses we observed in the lateral thalamus were inhibitory. It is therefore quite possible that the visceral inputs to, at least, VPL may play a modulatory role. However, this remains to be directly tested.

On the other hand, in most lateral thalamic neurons both the inhibitory and excitatory visceral responses adequately coded stimulus duration and intensity. The population responses for inhibition and excitation also show that the region as a whole can gradedly represent at least the visceral stimulus intensity. This implies that these neurons possess the necessary information to participate in the discrimination of visceral stimuli.

\section{Local versus distributed representation}

Individual and population responses of the lateral thalamic cells are consistent for their participation in coding visceral stimulus intensity. However, the large number of improper viscerovisceral and somatovisceral interactions observed in individual neurons may be taken as evidence for these units not participating in the localization of visccral stimuli. We propose an alternate explanation.

We assume that the improper interactions provide the first convincing evidence for the common observation that visceral stimulus localization is generally poor. Thus, we propose that the lateral thalamus does participate in visceral stimulus localization. Discrimination between somatic and visceral inputs is achieved by the different modes of representation used for the two types of inputs. Clearly, somatic representation in the lateral thalamus, and the regions connected to it (SI and SII), is achieved by a local partially overlapping representation, where a small group of neighboring neurons signals multiple parameters of the somatosensory stimuli. On the other hand, visceral stimulation activates and inhibits many lateral thalamic neurons with diverse somatic receptive fields, distributed throughout the region. This can act as a means for multiplexing information from visceral and somatic inputs at a common site, and as a means for discriminating between them. Thus, we propose that activation of a local contiguous group of cells results in somatosensory perceptions, while activation and inhibition of a much larger number of cells throughout VPL and VPM results in visceral perceptions. Discrimination between viscera is then achieved by a highly overlapping, distributed population pattern code (McClelland and Rumelhart, 1986), where subtle, seemingly random, changes in individual responses result in an overall change in the populational representation that shifts the percept from one viscus to another. This type of representation is reminiscent of odorant coding in the olfactory system, where individual neurons respond to a large variety of odorants, the locations of neurons responsive to a given odorant are randomly distributed, but the neuronal population response can accurately discriminate between odorants as shown by behavioral studies.

\section{Referred pain}

If visceral localization uses a distributed population code then this model should be able to explain referred pain. Referred pain is the projection of visceral pain to somatic structures. For example, ischemic events in the heart are experienced as transferred pain on the left shoulder region or even on the left jaw. These somatic areas are well known by physicians who use them as a diagnostic tool for visceral disturbances.

We hypothesize that peripheral chronic visceral injury results, like in somatic injury, in sensitization of dorsal horn neurons (Woolf, 1991). The somatovisceral interactions at the spinal cord level and on spinothalamic cells are generally organized more precisely than the dorsal column organization (see above). Therefore, central sensitization will be reflected in the thalamus in stronger activation of a contiguous group of cells in a region sharing somatic segmental inputs with the irritated viscus. The extent to which this activation becomes more localized, that is, overrides the dorsal column and brainstem inputs to the lateral thalamus, will be the factor determining the experience of referred pain. In brief, we propose that the mechanism for referred pain is a reorganization of coding of visceral representation in the lateral thalamus: by switching from a distributed representation to a local representation, the percept is switched from the viscus to the somatic body part that shares spinal segmental inputs. A number of observations arc consistent with this model.

As shown in the rat, the nociceptive transmission seems me- 
diated mainly through NMDA receptors and non-nociceptive transmission exhibits both non-NMDA (phasic inputs) and NMDA (tonic inputs) receptor-mediated transmission (Salt and Eaton, 1989; Eaton and Salt, 1990). Morcover, Ralston and Ralston (1992a,b) have recently shown that in the monkey, spinothalamic terminals contact primarily (more than $85 \%$ ) cortically projecting cells and avoid contacting local GABAergic neurons. In contrast, medial lemniscal terminations usually $(>90 \%)$ contact both cortically projecting cells and local GABAergic interneurons. Therefore, the pharmacology of somatic nociceptive transmission involves primarily NMDA receptors and seems to avoid GABAergic interneurons. Since the somatic non-nociceptive transmission in the thalamus involves both GABAergic and non-NMDA receptors, we propose that its connectivity is relatively fixed. In contrast, the somatic nociceptive connectivity may be modulated much more readily with changes in peripheral activity. Thus, chronic activation of visceral afferents will enhance the synaptic strengths of the spinothalamic inputs more readily than the synaptic strengths of the medial lemniscal inputs.

Our model also explains the fact that, in the awake human with an intact thalamus, electrical stimulation of the somatosensory thalamus gives rise to purely somatic sensations (e.g., Halliday and Logue, 1972; Dostrovsky et al., 1991; Lenz et al., in press). This would be a reflection of the focal activation of a small group of cells. Interestingly, Lenz (personal communication) reported that electrical stimulation in the lateral sensory thalamus in a patient with chronic leg pain (due to arachnoiditis) and angina, that is, visceral pain, reproduced the perception of the visceral pain and the leg pain, without the cardiac pathology that normally elicited this perception. Using our model, this result may be taken as evidence that the shift from distributed to local representation does occur for visceral inputs during chronic activation. With chronic afferent activity, synaptic strengthening takes place for somatic and visceral inputs, and as a result, focal electrical stimulation in chronic pain patients gives rise to both somatic and visceral sensations.

\section{References}

Aidar O, Geohegan WA, Ungewitter LH (1952) Splanchnic afferent pathways in the central nervous system. J Neurophysiol 15:131-138.

Akbarian S, Grüsser O-J, Guldin WO (1992) Thalamic Connections of the vestibular cortical fields in the squirrel morkey (Saimiri sciureus). J Comp Neurol 326:423-441.

Ammons WS, Giradot M-N, Foreman RD (1985) $T_{2}-T_{5}$ spinothalamic neurons projection to medial thalamus with viscerosomatic input. J Neurophysiol 54:73-89.

Apkarian AV, Shi T (1994) Squirrel monkey lateral thalamus. I. Somatic nociresponsive neurons and their relation to spinothalamic terminals. J Neurosci 14:6779-6795.

Asato F, Yokota T (1989) Responses of neurons in nucleus ventralis posterolateralis of the cat thalamus to hypogastric inputs. Brain Res 488:135-142.

Bahns E, Ernsberger U, Jänig W, Nelke A (1986) Functional characteristics of lumbar visceral afferent fibres from the urinary bladder and the urethra in the cat. Pfluegers Arch 407:510-518.

Bahns E, Halsband U, Jänig W (1987) Responses of sacral visceral afferents from the lower urinary tract, colon and anus to mechanical stimulation. Pfluegers Arch 410:296-303.

Berkley KJ, Scofield SL (1990) Relays from the spinal cord and solitary nucleus through the parabrachial nucleus to the forebrain in the cat. Brain Res 529:333-338.

Berkley KJ, Hubscher CH, Wall PD (1993a) Neuronal responses to stimulation of the cervix, uterus, colon, and skin in the rat spinal cord. J Neurophysiol 69:545-556.

Berkley KJ, Guilbaud G, Benoist J-M, Gautron M (1993b) Responses of neurons in and near the thalamic ventrobasal complex of the rat to stimulation of uterus, cervix, vagina, colon, and skin. J Neurophysiol 69:557-568.

Blomqvist A, Wu MA, Berkley KJ (1989) Spinal input to the parabrachial nucleus in the cat. Brain Res 480:29-36.

Brennan TJ, Oh UT, Hobbs SF, Garrison DW, Foreman RD (1989) Urinary bladder and hindlimb afferent input inhibits activity of primate $T_{2}-T_{5}$ spinothalamic tract neurons. J Neurophysiol 61:573-588.

Brüggemann J, Vahle-Hinz C, Kniffki K-D (1993) Representation of the urinary bladder in the lateral thalamus of the cat. J Neurophysiol 70:482-491.

Brüggemann J, Vahle-Hinz C, Apkarian AV, Kniffki K-D (in press) Somato-visceral convergence in thalamic regions of the cat. $J$ Neurophysiol, in press.

Brüggemann J, Vahle-Hinz C, Kniffki K-D (in press) Projections from the pelvic nerve to the periphery of the cat's thalamic ventral posterolateral nucleus and adjacent regions of the posterior complex. $J$ Neurophysiol, in press.

Carstens E, Yokota T (1980) Viscerosomatic convergence and responses to intestinal distension of neurons at the junction of midbrain and posterior thalamus in the cat. Exp Neurol 70:392-402.

Cechetto DF (1987) Central representation of visceral function. Fed Proc 46:17-23.

Cechetto DF, Saper CB (1987) Evidence for a viscerotopic sensory representation in the cortex and thalamus in the rat. J Comp Neurol 262:27-45

Cervero F (1983) Somatic and visceral inputs to the thoracic spinal cord of the cat: effects of noxious stimulation of the biliary system. J Physiol (Lond) 337:51-67.

Cervero F, Iggo A (1978) Natural stimulation of urinary bladder afferents does not affect transmission through lumbosacral spinocervical tract neurones in the cat. Brain Res 156:375-379.

Cervero F, Jänig W (1992) Visceral nociceptors: a new world order? Trends Neurosci 15:374-378.

Cervero F, Tattersall JEH (1986) Somatic and visceral sensory integration in the thoracic spinal cord. In: Progress in brain research, Vol 67 (Cervero F, Morrison JFB, eds), pp 189-205. Amsterdam: Elsevier.

Chandler MJ, Hobbs SF, Qing-Gong FU, Kenshalo DR, Blair RW, Foreman DR (1992) Responses of neurons in ventroposterolateral nucleus of primate thalamus to urinary bladder distension. Brain Res $571: 26-34$

Chernigovskiy VN (1967) Interoceptors. Washington, DC: American Psychological Association.

Chung JM, Lee KH, Surmeier KJ, Sorkin LS, Kim J, Willis WD (1986) Response characteristics of neurons in the ventral posterior lateral nucleus of the monkey thalamus. J Neurophysiol 56:370-390.

Davis KD, Dostrovsky JO (1988) Properties of feline thalamic neurons activated by stimulation of the middle meningeal artery and sagittal sinus. Brain Res 454:89-100.

Dell P, Olson R (1951b) Projections thalamiques, corticales et cérébelleuses des afferrences viscérales vagales. Soc Biol 145:1084-1088.

Dell P, Olson R (1951a) Projections "secondaires" mésencéphaliques, diencéphaliques et amygdaliennes des afférances viscérales vagales. Soc Biol 145:1088-1091.

Dostrovky JO, Wells FEB, Tasker RR (1991) Pain evoked by stimulation in human thalamus. In: International symposium on processing nociceptive information (Sjigenaga Y, ed). Amsterdam: Elsevier.

Eaton SA, Salt TE (1990) Thalamic NMDA receptors and nociceptive sensory synaptic transmission. Neurosci Lett 110:297-302.

Emmers R (1966) Separate relays of tactile, pressure, thermal, and gustatory modalities in the cat thalamus. Proc Soc Exp Biol Med 121: 527-531.

Emmers R, Akert K (1963) A stereotaxic atlas of the brain of the squirrel monkey (Saimiri sciureus). Madison: University of Wisconsin.

Feller W (1956) An introduction to probability theory and its applications, Vol 1, 2d ed, pp 36-41. New York: Wiley.

Floyd K, McMahon SB, Morrison JFB (1982) Inhibitory interactions between colonic and visical afferents in the micturition reflex of the cat. J Physiol (Lond) 322:45-52.

Foreman RD, Hancock MB, Willis WD (1981) Responses of spinothalamic tract cells in the thoracic spinal cord of the monkey to cutaneous and visceral inputs. Pain 11:149-162.

Foreman RD, Blair RW, Weber RN (1984) Viscerosomatic convergence onto T2-T4 spinoreticular, spinoreticular-spinothalamic, and spinothalamic tract neurons in the cat. Exp Neurol 85:597-619. 
Häbler H-J, Jänig W, Koltzenburg M (1988) Dichotomizing unmyelinated afferents supplying pelvic viscera and pcrineum are rare in the sacral segments of the cat. Neurosci Lett 94:1 19-124.

Halliday AM, Logue V (1972) Painful sensations evoked by electrical stimulation in the thalamus. In: Neurophysiology studied in man (Somjen GG, ed), pp 221-230. Exc Med Amsterdam.

Hobbs SF, Oh UT, Brennan TJ, Chandler MJ, Kim KS, Foreman RD (1990) Urinary bladder and hindlimb stimuli inhibit $T_{1}-T_{6}$ spinal and spinoreticular cells. Am J Physiol 258:10-20.

Hobbs SF, Chandler MJ, Bolser DC, Foreman RD (1992) Segmental organization of visceral and somatic input onto $\mathrm{C}_{3}-\mathrm{T}_{6}$ spinothalamic tract cells of the monkey. J Neurophysiol $68: 1575-1588$.

Hoeber PB (1940) Selected writings of Sir Charles Sherrington: a testimonial presented by the neurologists forming the guarantors of the journal Brain, pp 31-91, On the distribution of the sensory nerveroots. New York: Harper.

Hubscher CH, Berkley KJ (1992) Neuronal responses to stimulation of uterus, cervix and vaginal canal in rat gracile nucleus. Soc Neurosci Abstr 18:494.

Jänig W, Morrison JFB (1986) Functional properties of spinal visceral afferents supplying abdominal and pelvic organs, with special emphasis on visceral nociception. In: Progress in brain research, Vol 67 (Cervero F, Morrison JFB, eds), pp 87-114. Amsterdam: Elsevier.

Jiménez-Montaño MA (1984) On the syntactic structure of protein sequences and the concept of grammar complexity. Bull Math Biol 46:641-659.

Kaas JH, Nelson RJ, Sur M, Dykes RW, Merzenich MM (1984) The somatotopic organization of the ventroposterior thalamus of the squirrel monkey, Saimiri sciureus. J Comp Neurol 226:111-140.

Kuo DC, de Groat WC (1985) Primary afferent projections of the major splanchnic nerve to the spinal cord and gracile nucleus of the cat. J Comp Neurol 231:421-434.

Lenz FA, Seike M, Lin YC, Baker FH, Richardson RT, Gracely RH (in press) Thermal and pain sensations evoked by microstimulation in the area of the human ventrocaudal nucleus (Vc). J Neurophysiol, in press.

McClelland JL, Rumelhart DE (1986) A distributed model of human learning and memory. In: Parallel distributed processing 2 (Rumelhart DE, McClelland JM, the PDP Research Group, eds), pp 170-215. Cambridge, MA: MIT Press.

McLeod JG (1958) The representation of the splanchnic afferent pathways in the thalamus of the cat. J Physiol (Lond) 140:462-478.

McMahon SB, Morrison JFB (1982a) Spinal neurones with long projections activated from the abdominal viscera of the cat. $J$ Physiol (Lond) 322:1-20.

McMahon SB, Morrison JFB (1982b) Two groups of spinal interneurones that respond to stimulation of the abdominal viscera. J Physiol (Lond) 322:21-34.

Milne RJ, Foreman RD, Giesler GJ Jr, Willis WD (1981) Convergence of cutaneous and pelvic visceral nociceptive inputs onto primate spinothalamic neurons. Pain 11:163-183.

Milne RJ, Foreman RD, Giesler GJ Jr, Willis WD (1983) Viscerosomatic convergence onto primate spinothalamic neurons: an explanation for the referral of visceral pain. In: Advances in pain research and therapy 5 (Bonica JJ et al., eds), pp 131-137. New York: Raven.

Mufson EJ, Mesulam MM (1984) Thalamic connections of the insula in the rhesus monkey and comments on the paralimbic connectivity of the medial pulvinar nucleus. J Comp Neurol 227:109-120.

Ness TJ, Gebhart GF (1990) Visceral pain. Pain 41:167-234.

Patton HD, Amassian VE (1951) Thalamic relay of splanchnic afferent fibers. Am J Physiol 167:815-816.

Person RJ (1989) Somatic and vagal afferent convergence on solitary tract neurons in cat: electrophysiological characteristics. Neuroscience 30:283-295.

Ralston DD, Ralston HJ (1992a) Spinothalamic tract terminals in $M$. fascicularis: 3-dimensional computer-assisted reconstructions of synaptic relationships. Soc Neurosci Abstr 18:1018.

Ralston HJ, Ralston DD (1992b) Medial lemniscal terminals in $M$ fascicularis: 3-dimensional computer-assisted reconstructions of synaptic relationships. Soc Neurosci Abstr 18:1018.

Rapp PE, Goldberg G, Albano AM, Janicki MB, Murphy D, Niemeyer E, Jiménez-Montaño MA (1993) Using coarse-grained measures to characterize electromyographic signals. Int J Birfurc Chaos 3:525541 .

Rigamonti DD, De Michelle D (1977) Visceral afferent projection to the lateral cervical nucleus. In: Nerves and the gut (Brooks FP, Evans PW, eds), pp 327-333. Thorofare, NJ: Slack.

Rigamonti DD, Hancock MB (1974) Analysis of field potentials elicited in the dorsal column nuclei by splanchnic nerve A-beta afferents. Brain Res 77:326-329.

Rigamonti DD, Hancock MB (1978) Viscerosomatic convergence in the dorsal column nuclei of the cat. Exp Neurol 61:337-348.

Rogers RC, Novin D, Butcher LL (1979) Hepatic sodium and osmoreceptors activate neurons in the ventrobasal thalamus. Brain Res 168:398-403.

Ruch TC (1946) Visceral sensation and referred pain In: Howell's textbook of physiology, 15th ed (Fulton JF, ed), pp 385-401. Philadelphia: Saunders.

Rucker HK, Holloway JA, Keyser GF (1984) Response characteristics of cat spinothalamic tract neurons to splanchnic nerve stimulation. Brain Res 291:383-387.

Salt TE, Eaton SA (1989) Function of non-NMDA and NMDA receptors in synaptic responses to natural somatosensory stimulation in the ventrobasal thalamus. Exp Brain Res 77:646-652.

Sengupta JN, Kauvar D, Goyal RK (1989) Characteristics of vagal esophageal tension-sensitive afferent fibers in the opossum. J Neurophysiol 61:1001-1010.

Sengupta JN, Saha JK, Goyal RK (1990) Stimulus-response function studies of esophageal mechanosensitive nociceptors in sympathetic afferents of opossum. Neuroscience 64:796-812.

Sinclair DC, Weddell G, Feindel WH (1948) Referred pain and associated phenomena. Brain 71:184-211.

Taguchi H, Masuda T, Yokota T (1987) Cardiac sympathetic afferent input onto neurons in nucleus ventralis posterolateralis in cat thalamus. Brain Res 436:240-252.

Torrens M, Morrison JFB (1987) The physiology of the lower urinary tract. New York: Springer.

Willis WD (1985) The pain system. New York: Karger.

Woolf CJ (1991) Generation of acute pain: central mechanisms. $\mathrm{Br}$ Med Bull 47:523-533.

Yamamoto S, Sugihara S, Kuru M (1956) Microelectrode studies on sensory afferents in the posterior funiculus of cat. Jpn J Physiol 6:6885.

Yezierski RP, Broton JG (1991) Functional properties of spinomesencephalic tract (SMT) cells in the upper cervical spinal cord of the cat. Pain 45:187-196.

Yokota T, Masuda T, Taguchi 'H, Koyama N (1987) Viscerosomatic convergence onto nociceptive neurons in the shell region of nucleus ventralis posterolateralis. In: Fine afferent nerve fibers and pain (Schmidt RF, Schaible H-G, Vahle-Hinz C, eds), pp 427-437. Weinheim: VCH.

Zagami AS, Lambert GA (1990) Stimulation of cranial vessels excites nociceptive neurones in several thalamic nuclei of the cat. Exp Brain Res 81:552-566. 